\title{
EL LÉXICO DEL MAR EN COSTA RICA: ANÁLISIS GEOLINGÜÍSTICO (2)
}

\author{
Randi Korneliussen
}

\begin{abstract}
RESUMEN
El presente artículo es el producto de una investigación geolingüística realizada en localidades situadas en las costas atlántica y pacífica de Costa Rica, en donde la principal fuente de trabajo es la pesca. El trabajo consta de 43 mapas lingüísticos puntuales, y está dividido en dos partes. En la primera parte se presentaron los marcos teórico y metodológico del estudio, además de los primeros 18 mapas lingüísticos. En la segunda parte -que es la presente-se muestran los 25 mapas lingüísticos restantes, acompañados de una interpretación lingüístico-etnográfica y de la bibliografía.

Palabras clave: Léxico del mar, Costa Rica, mapas lingüísticos y etnográficos, análisis dialectológico
\end{abstract}

\begin{abstract}
The present article describes and analyses the vocabulary used by fishermen and sailors in Costa Rica, such as tasks related to the sea and the act of fishing. The linguistic material was gathered along the Caribbean and Pacific coasts by means of a geolinguistic field work. This is the second and concluding part of an article presenting 43 punctual linguistic maps. The theoretical frame and the first 17 maps were included in the last edition of this review, whereas the final 26 maps, followed by a linguistic interpretation and the references, are published in this issue.

Key words: Terms of the Sea, Costa Rica, linguistic and etnographic maps, dialectological analysis
\end{abstract}

Lic. Randi Korneliussen. Licenciada en Filología Española e Inglesa. Profesora en el Colegio Oystese Gymnas y Colegio Técnico de Norheimsund. Mediadora de conflictos para la región de Hordaland.

Correo electrónico: rankodyret@hotmail.com

Recepción: 13-04-2004

Aceptación: 24-05-2004 


\section{Introducción}

El presente artículo forma parte de una investigación de campo, de carácter geográfico-lingüístico, realizada en dieciséis localidades situadas a lo largo de las costas atlántica y pacífica de Costa Rica. En estas localidades se entrevistaron personas cuya principal fuente de trabajo era la pesca y actividades relacionadas con el mar. El trabajo está enmarcado dentro de los postulados de la disciplina geográfico-lingüística, tal como queda expuesta en los estudios de Alvar (1969, 1977, 1993), Montes Giraldo (1970, 1973, 1982) y Francis (1983), entre otros.

Este trabajo consta de 43 mapas lingüísticos puntuales y se ha dividido en dos secciones. En la primera sección (publicada en el número anterior de esta revista), se presentaron los marcos teórico y metodológico del estudio, además de los primeros 18 mapas lingüísticos. La segunda sección -que es la presente-muestra los 25 mapas lingüísticos restantes, acompañados de una interpretación linguiústico-etnográfica y de la bibliografía empleada.

Tal y como queda dicho en la sección anterior, la meta general del presente trabajo es llevar a cabo una investigación geográfico-lingüística sobre el vocabulario marinero de dichas regiones, lo cual incluye tanto el vocabulario usado para nombrar los fenómenos meteorológicos y las características geográficas de estas zonas, como el léxico relacionado con las actividades pesqueras y marineras. Los objetivos específicos son los siguientes:

1. Presentar el vocabulario recopilado en mapas lingüísticos que muestren su distribución geográfica ${ }^{1}$.

2. Interpretar el material para determinar zonas dialectales costeras y compararlas con la división establecida anteriormente por Agüero (1962) y Quesada (1992b).

3. Contribuir con la realización del Atlas Lingüístico-etnográfico de Costa Rica.

\section{Mapas lingüísticos y etnográficos (continuación)}



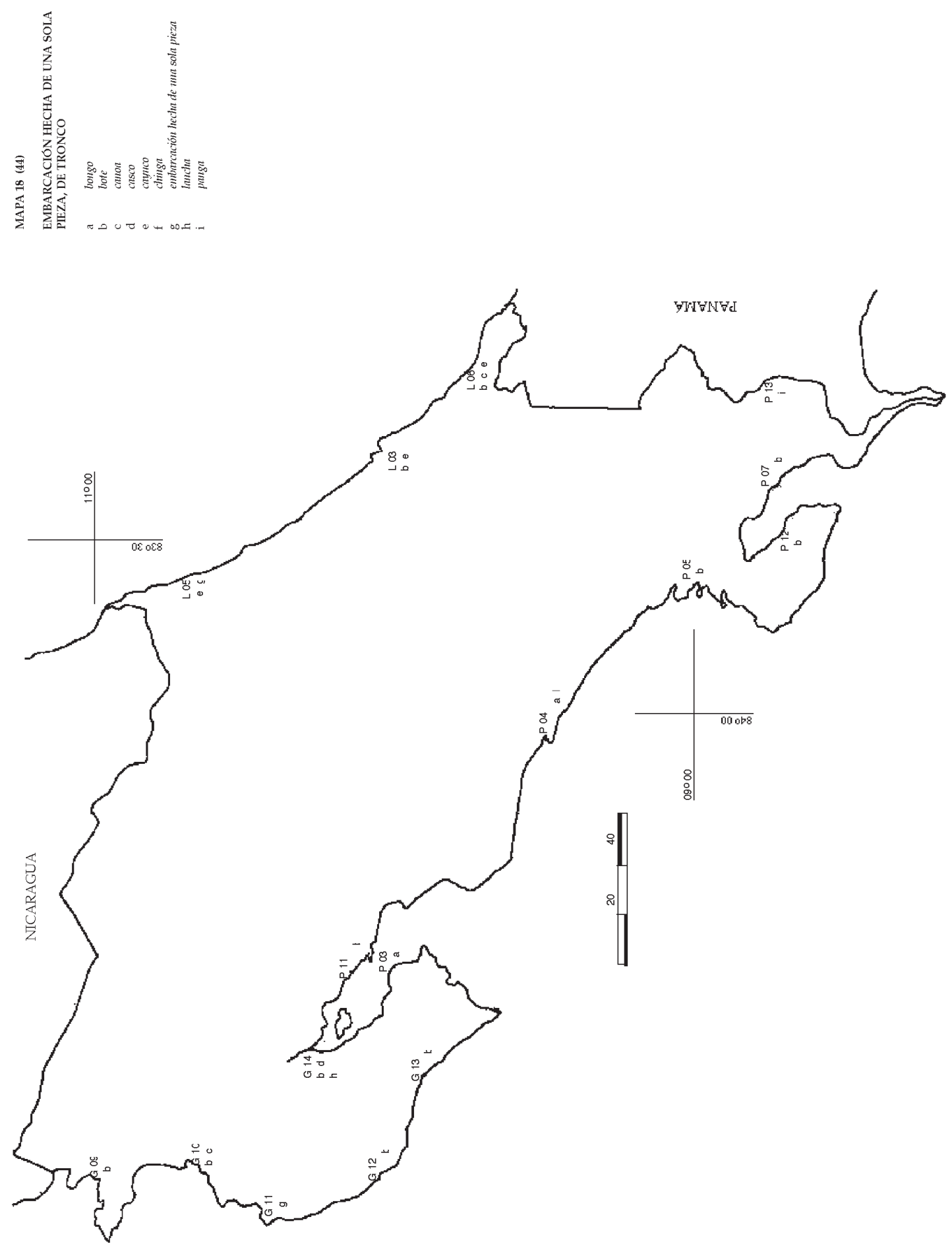

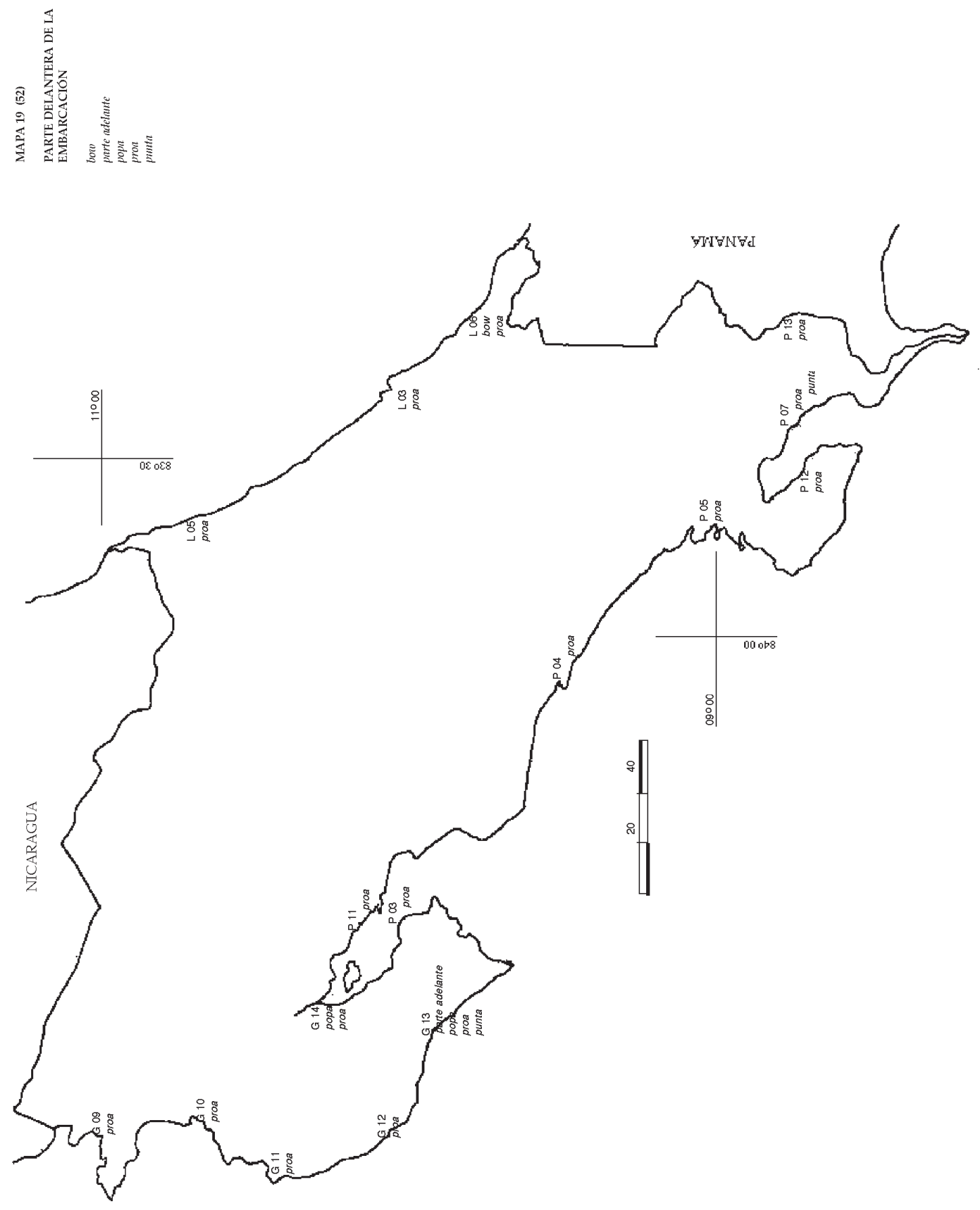

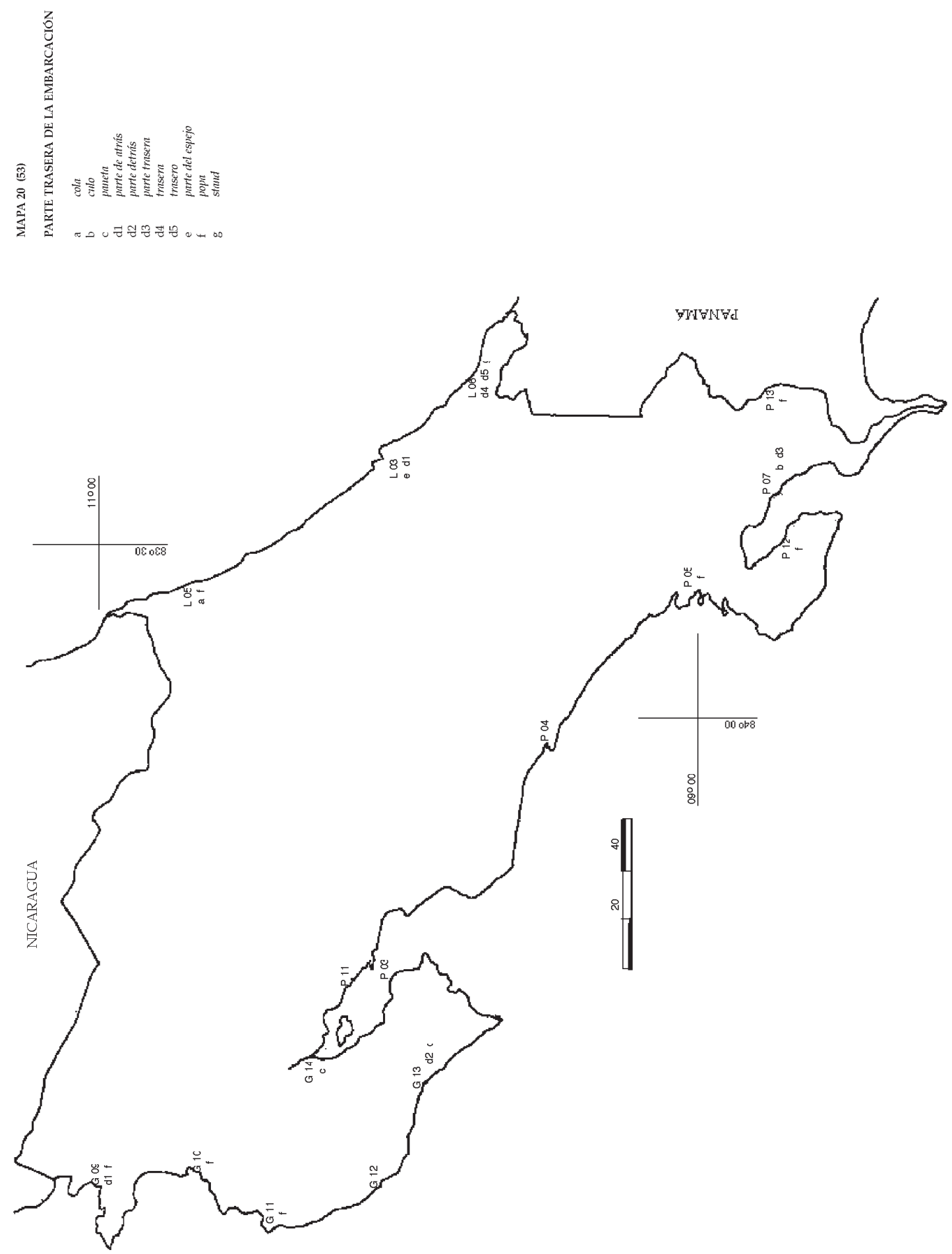

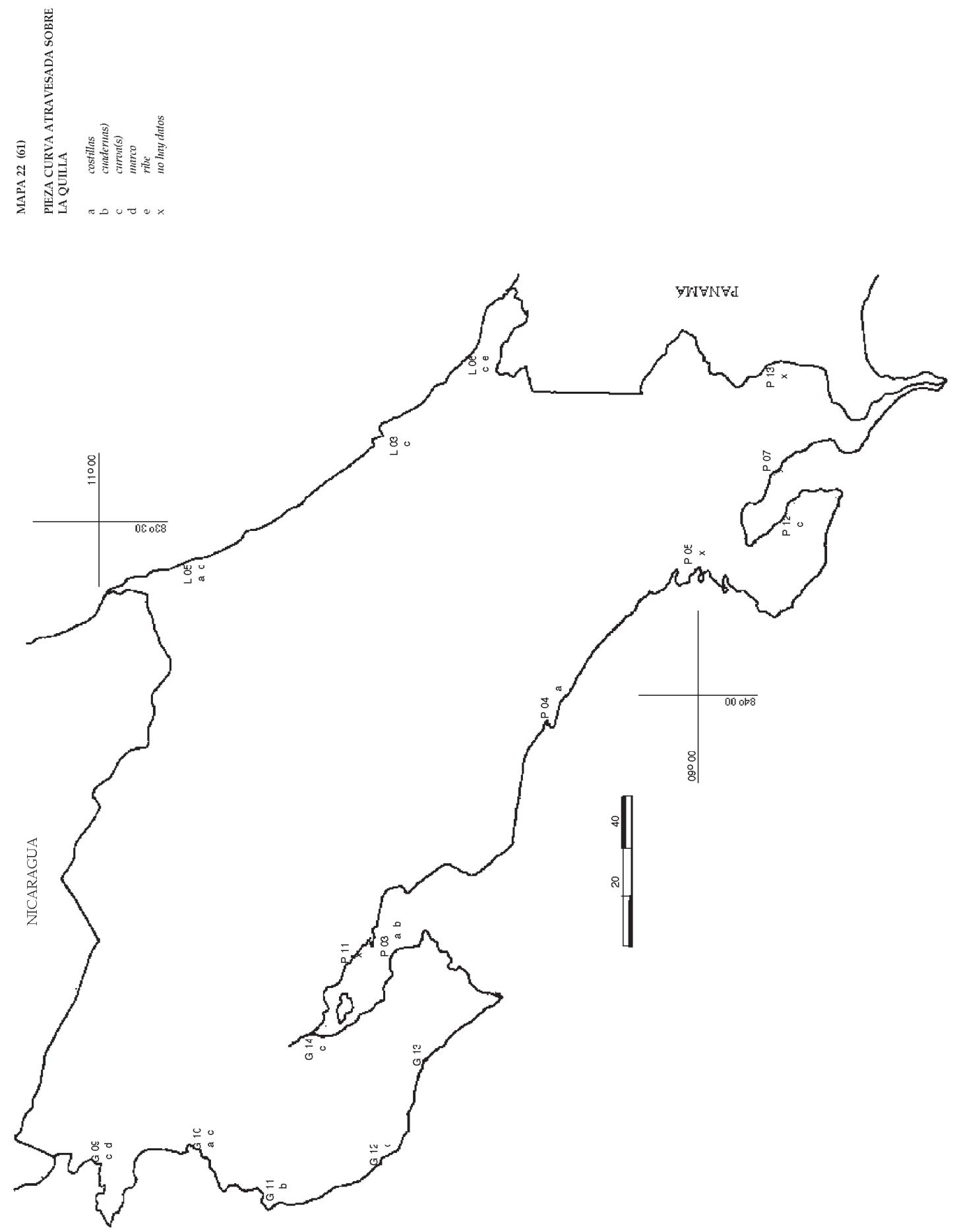

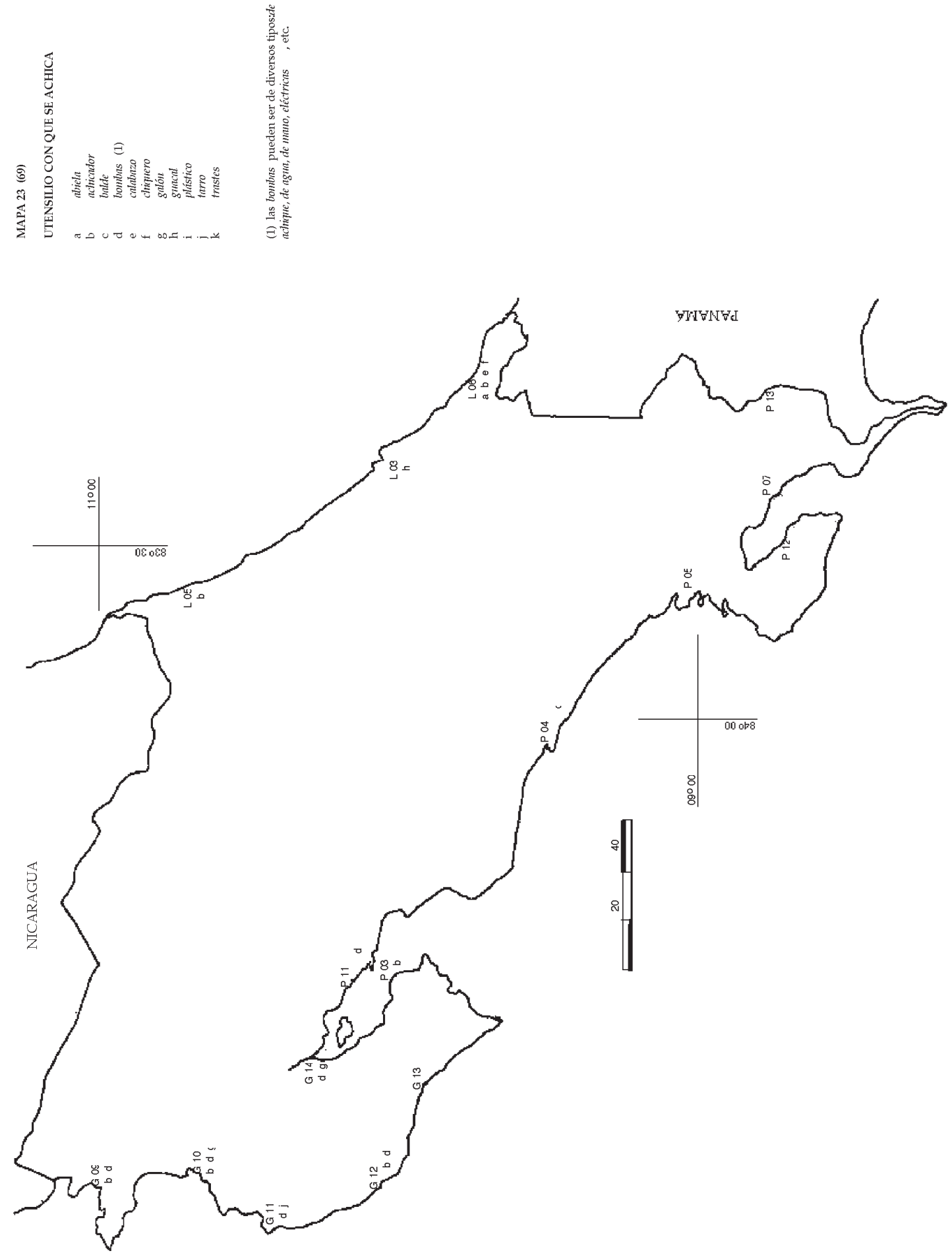

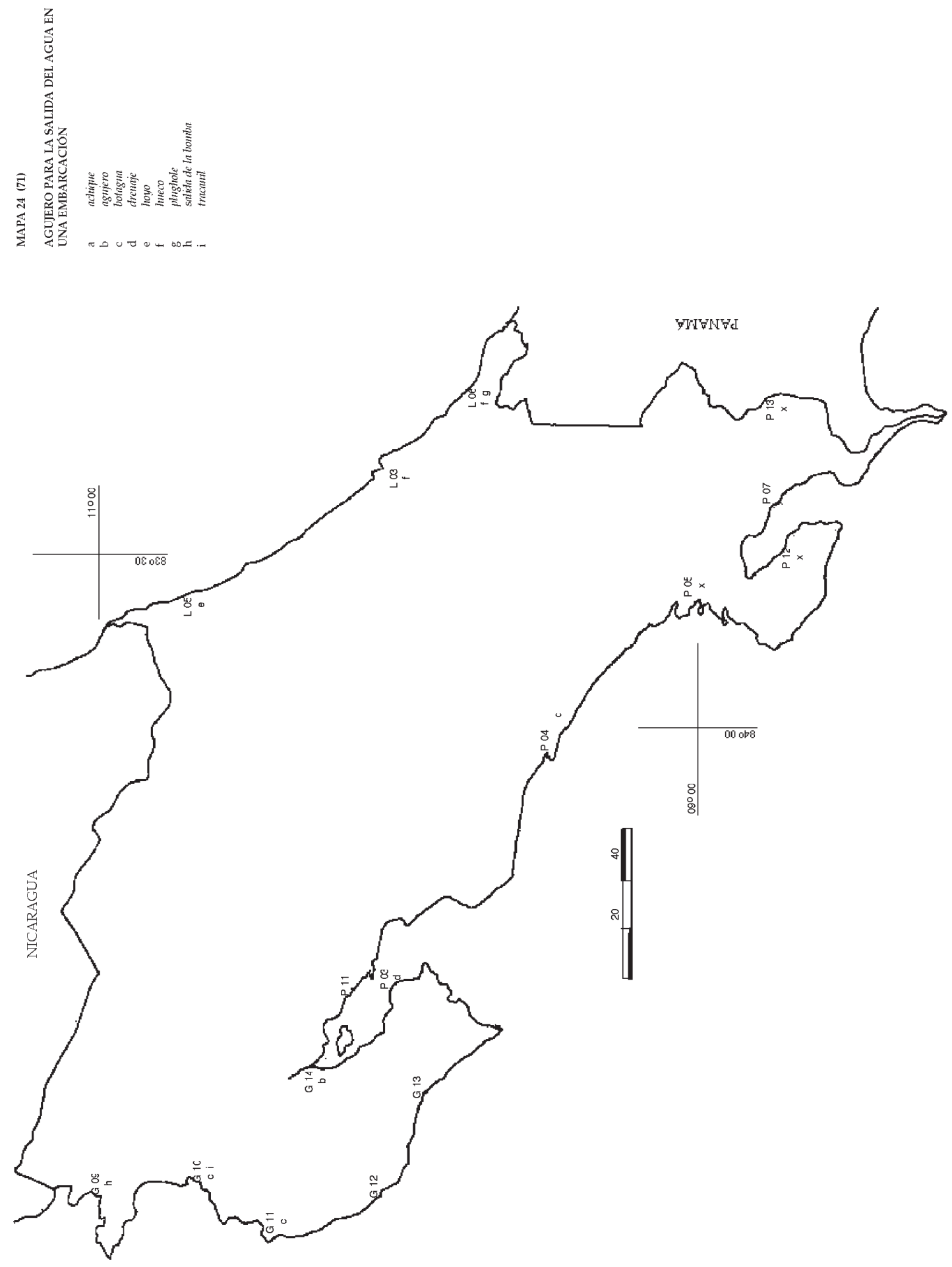

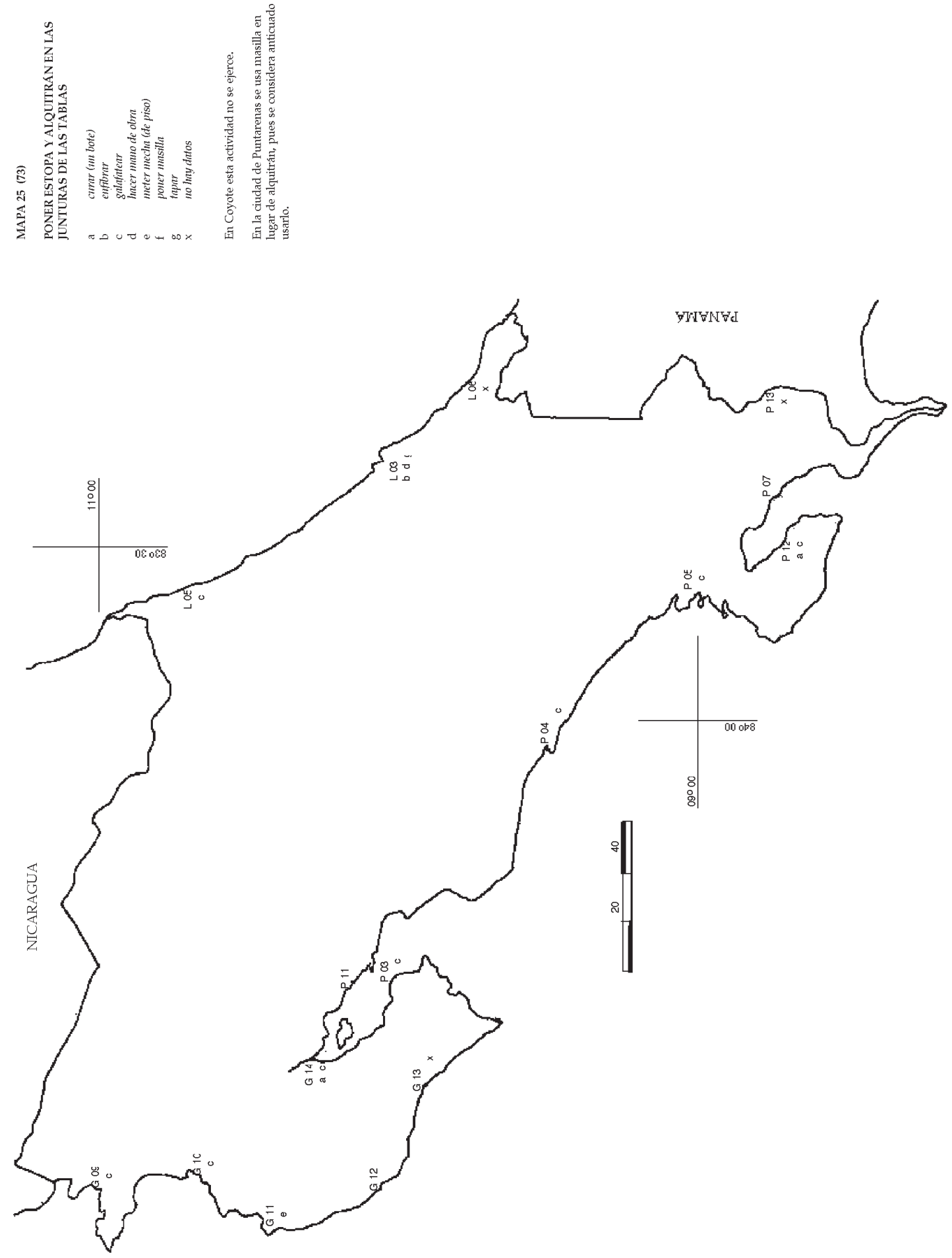

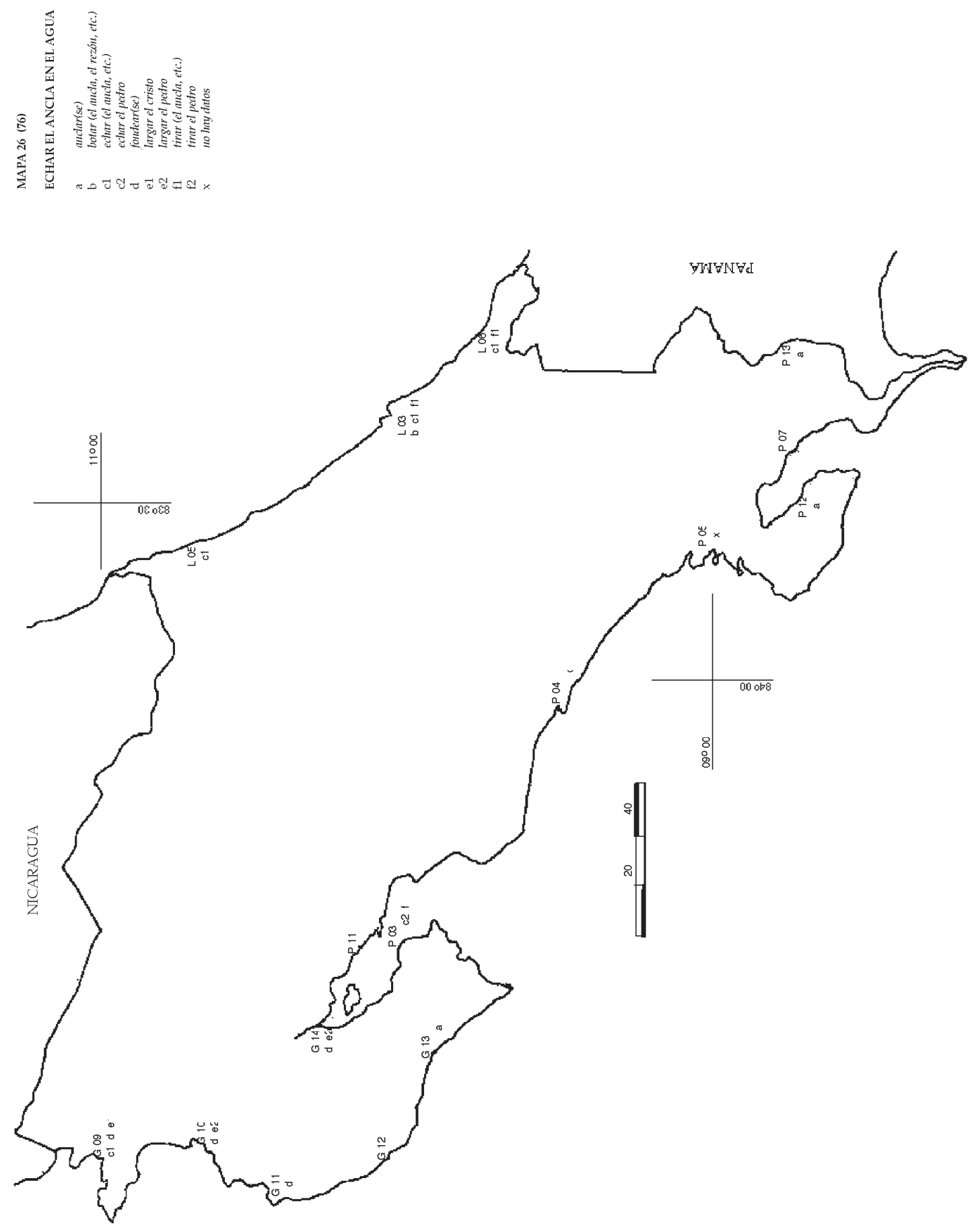
KORNELIUSSEN: El léxico del mar en Costa Rica: análisis geolingüístico (2)
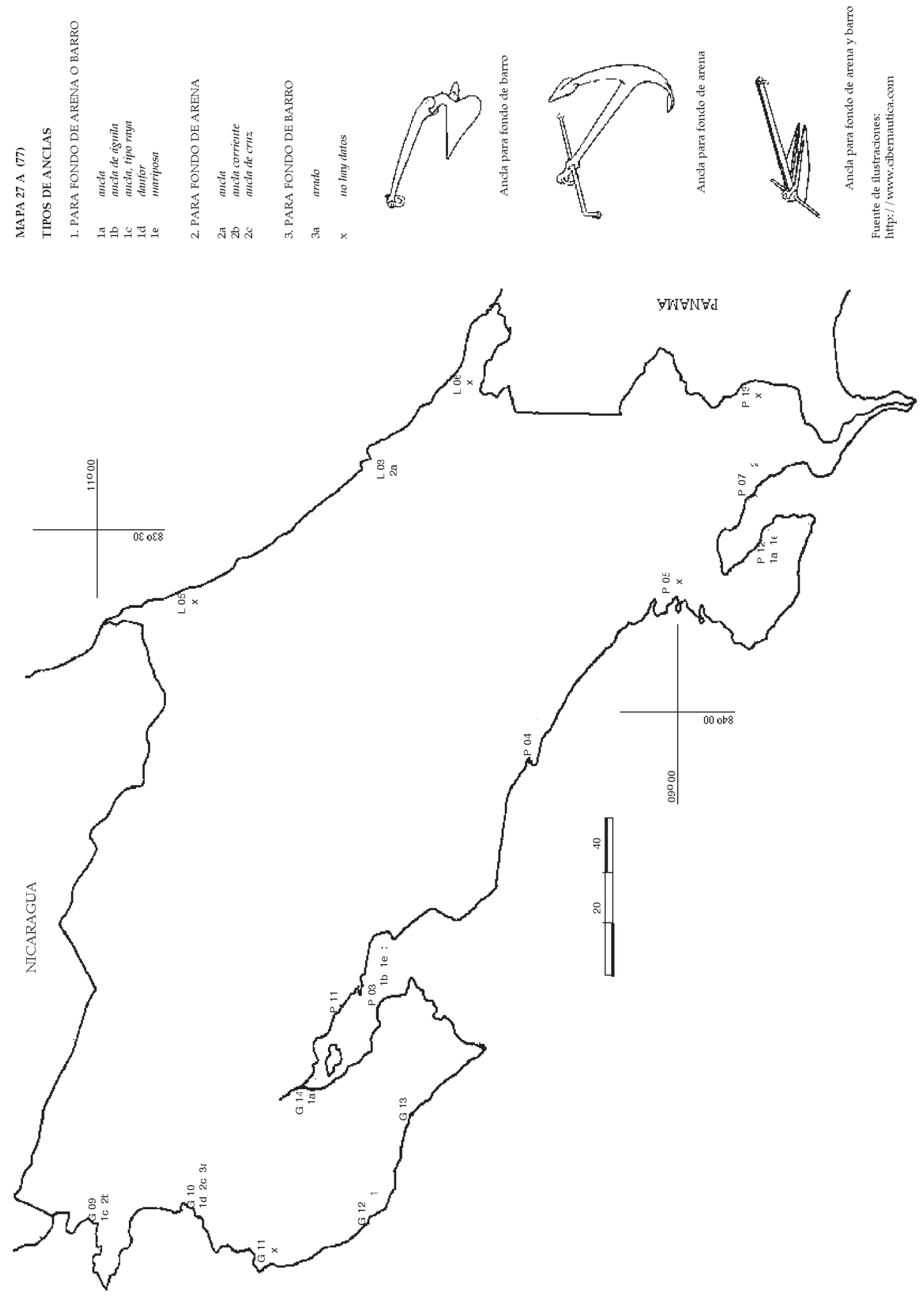

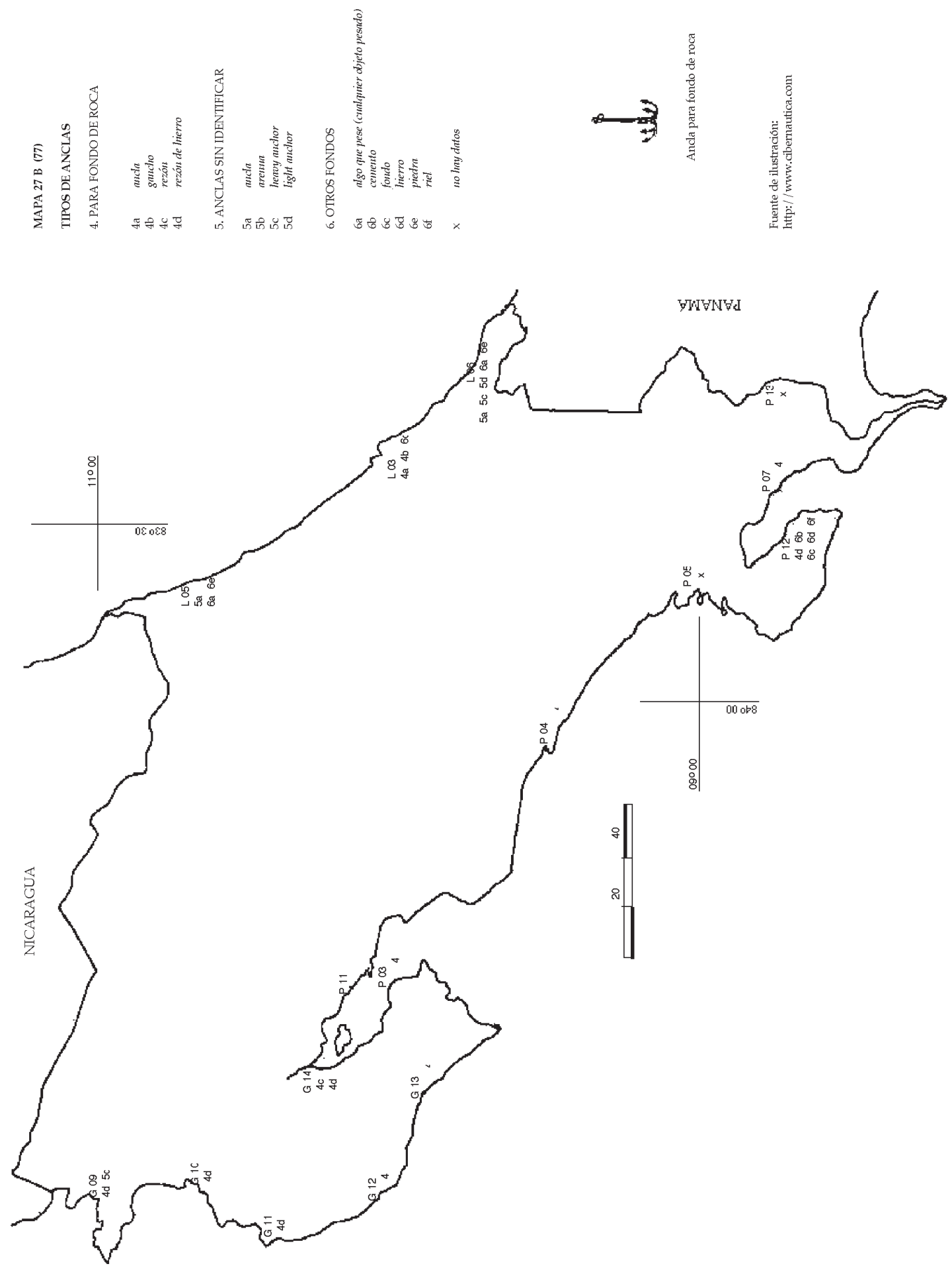

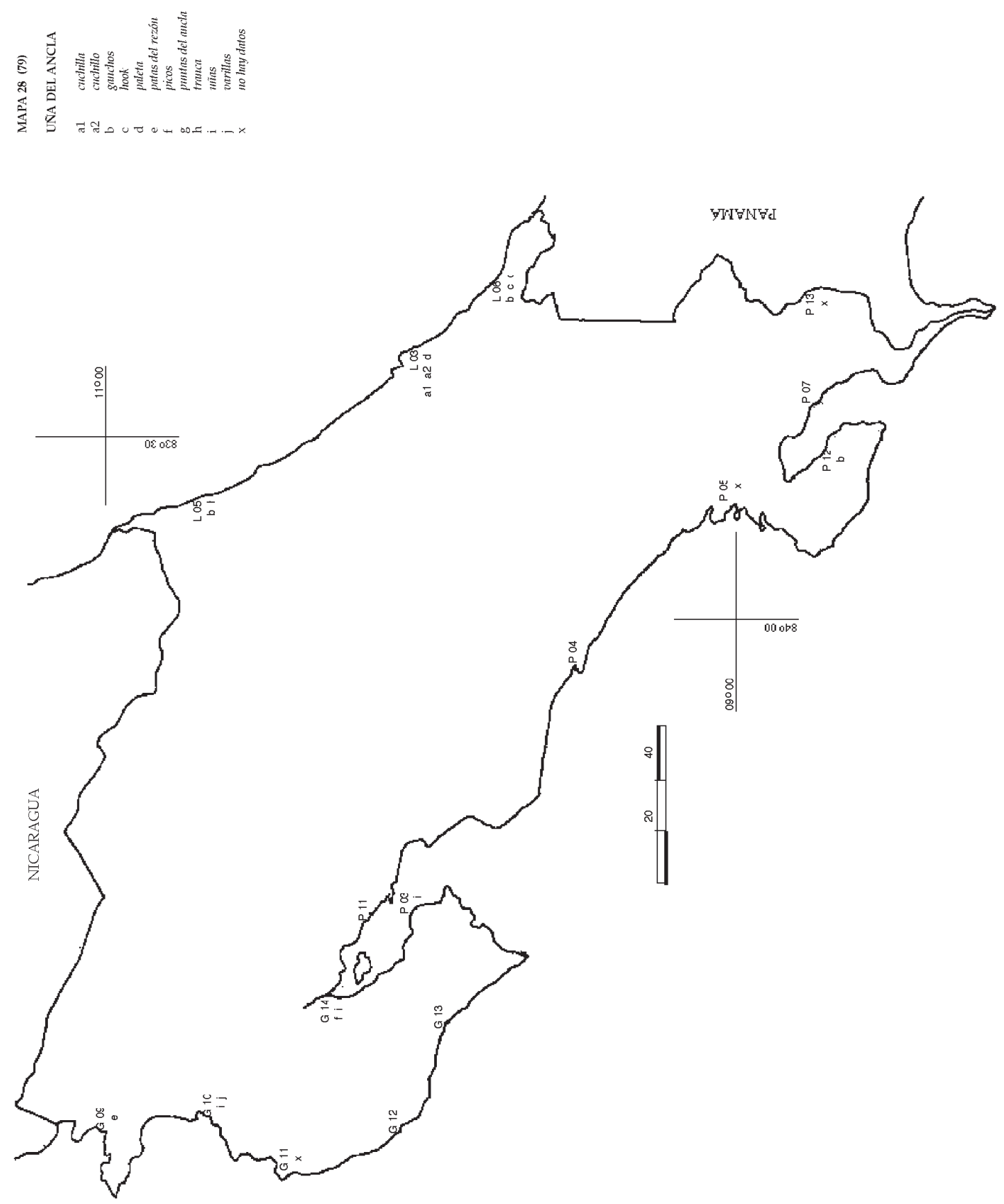

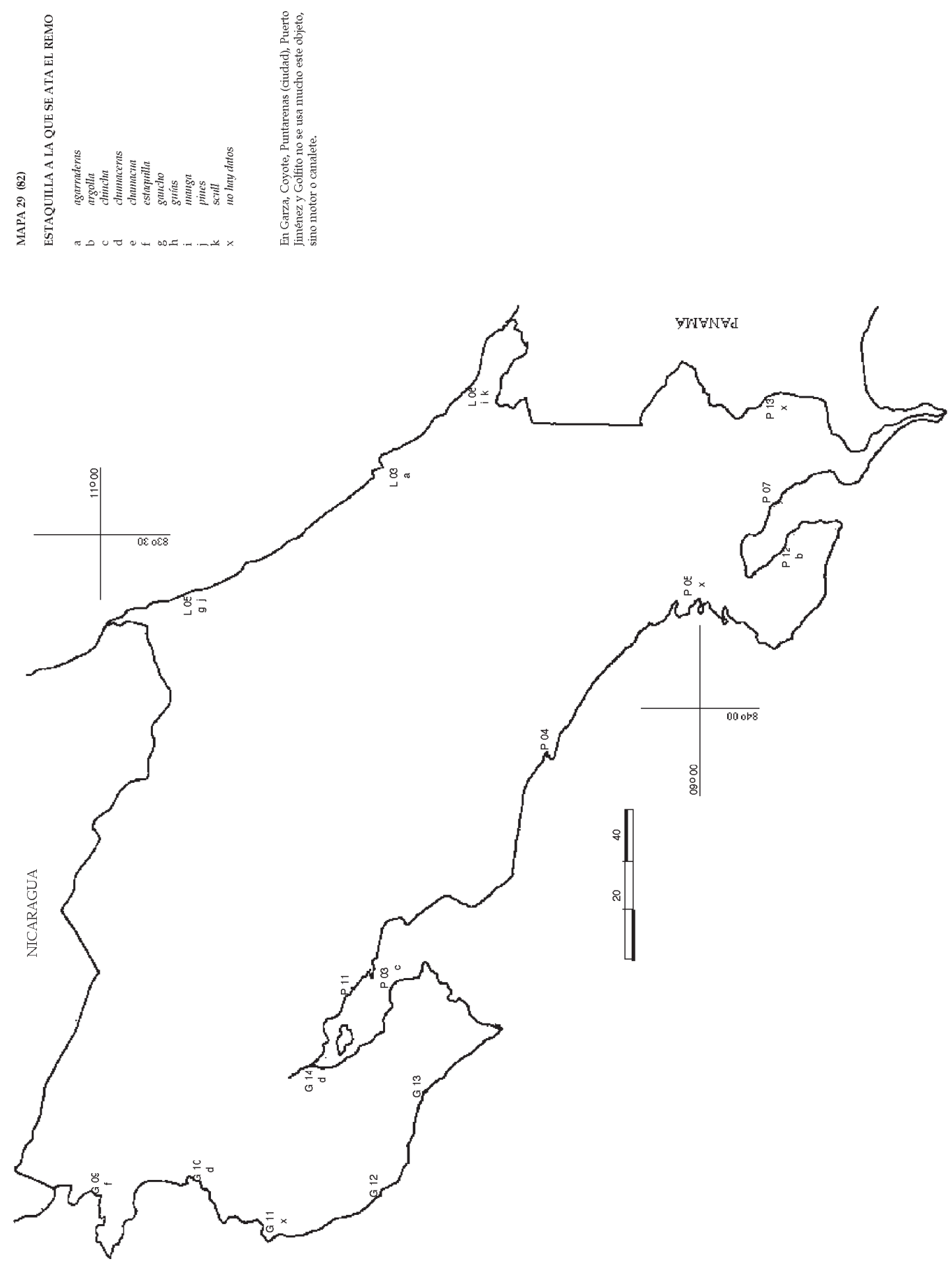

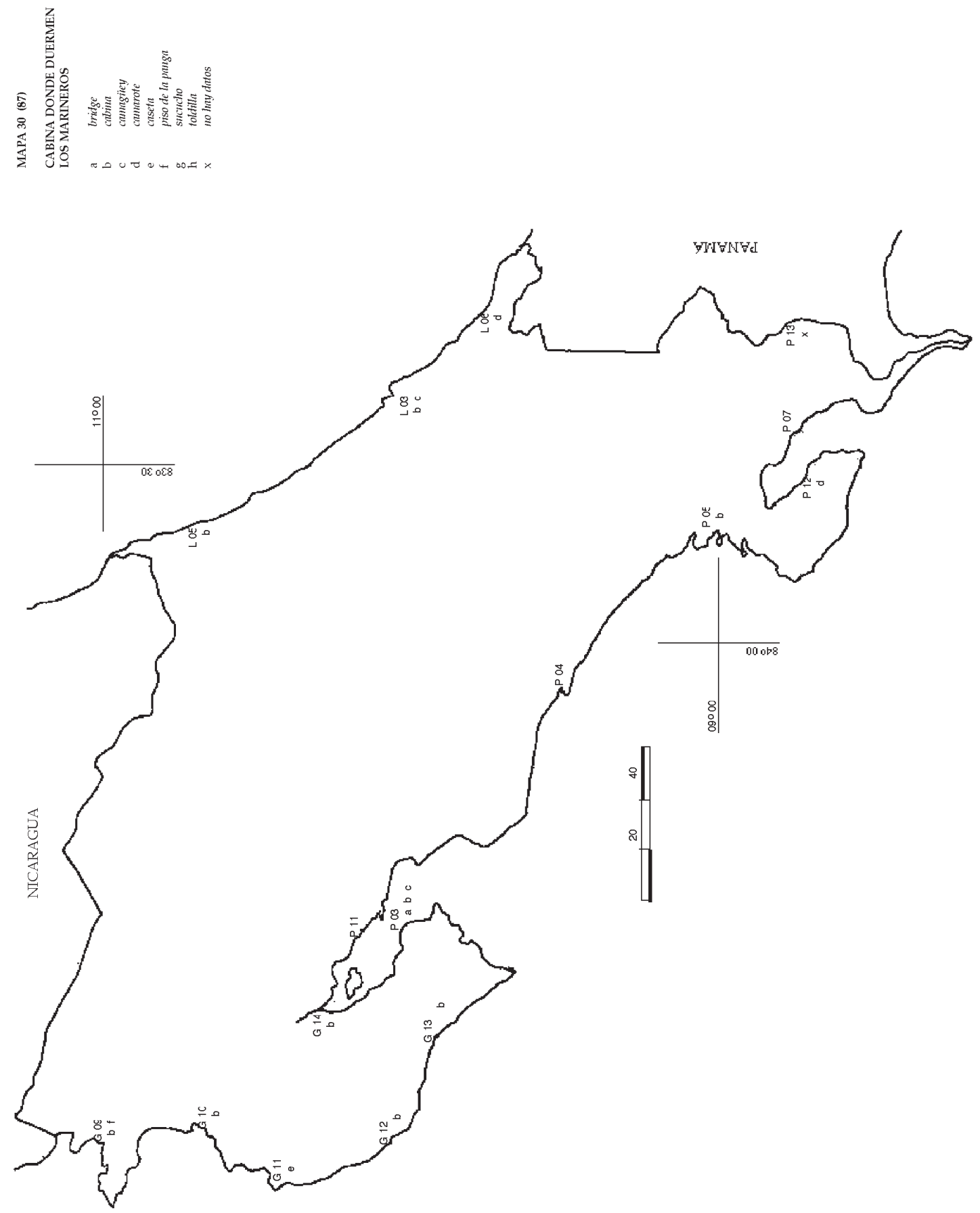

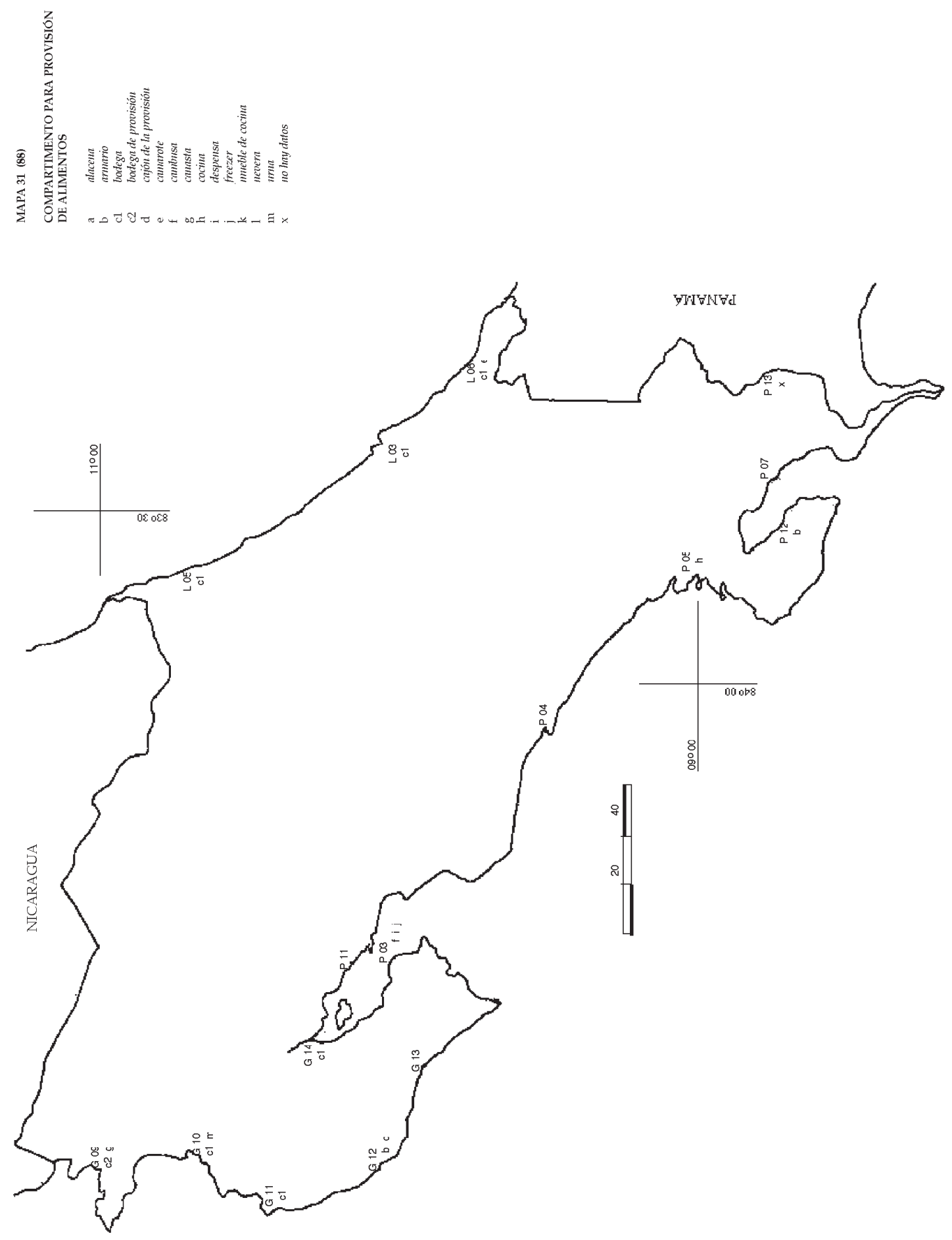

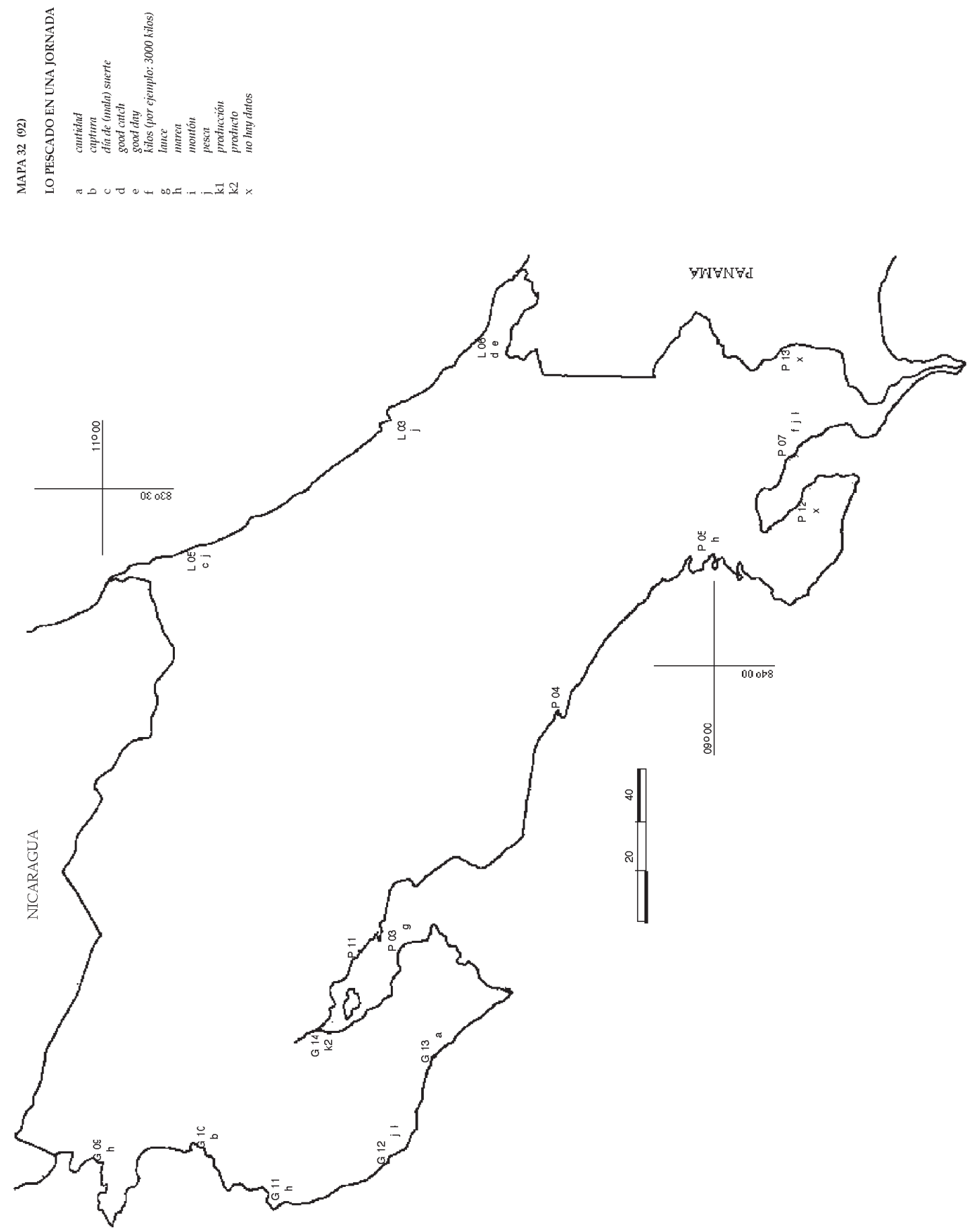

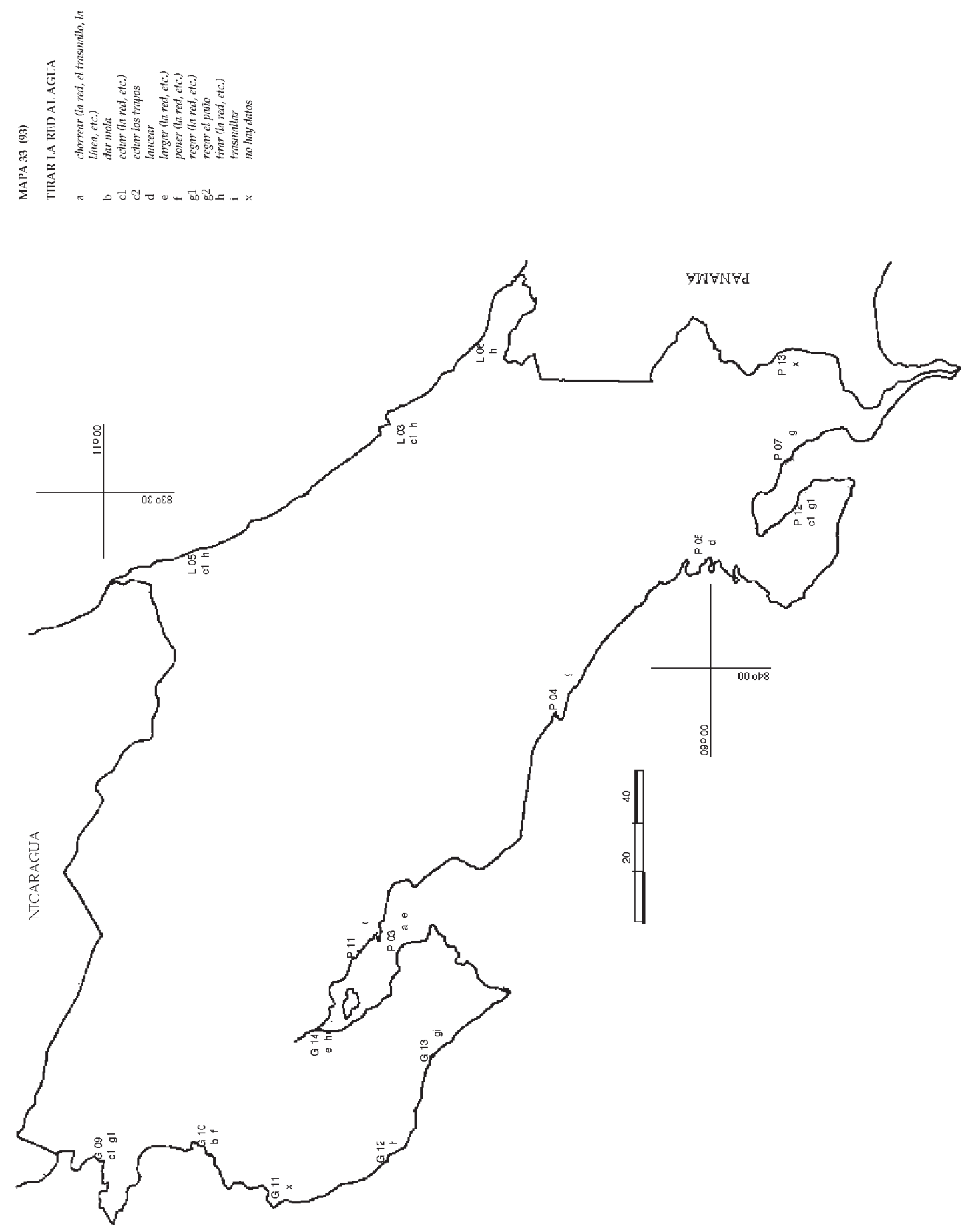

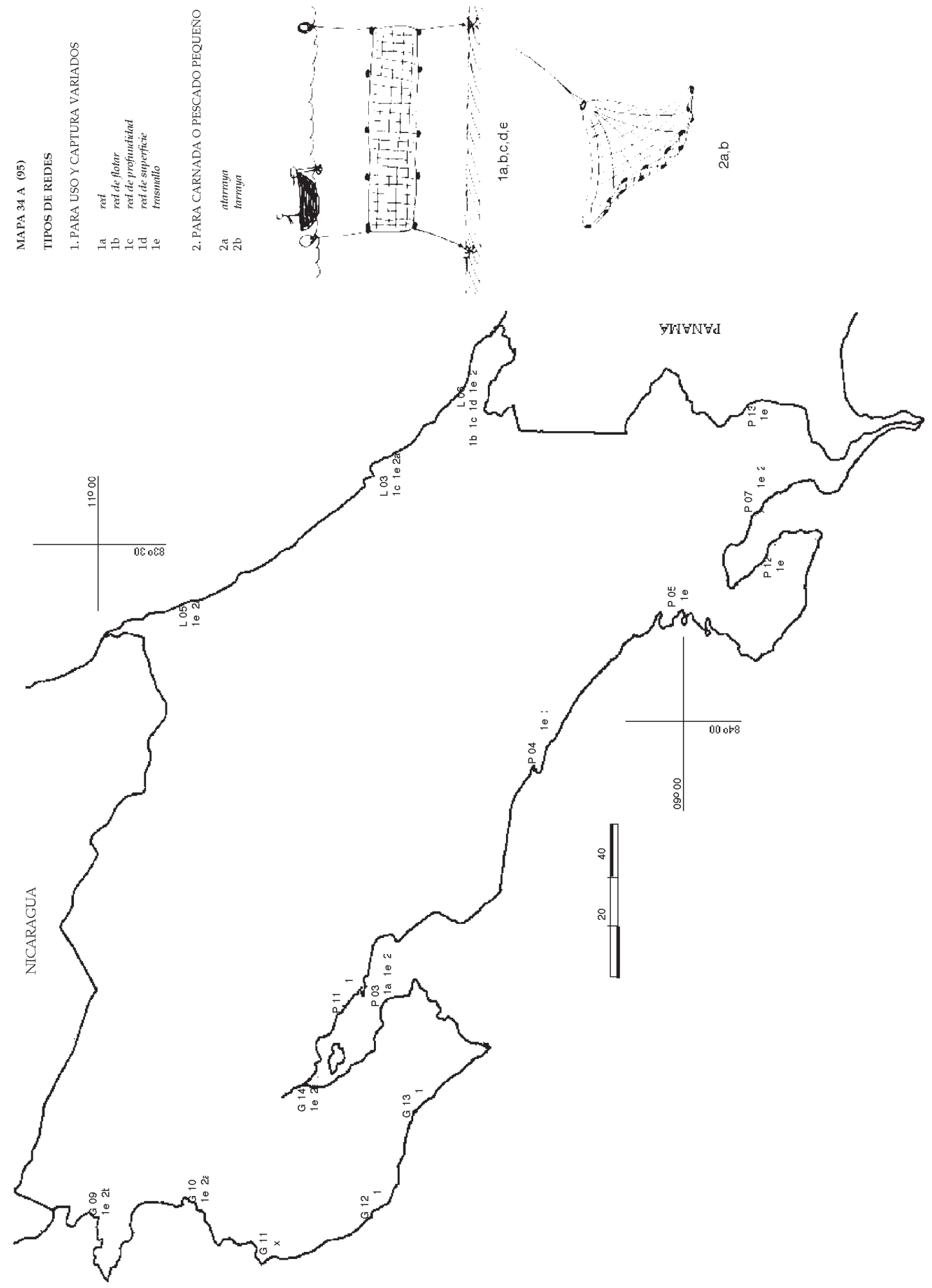

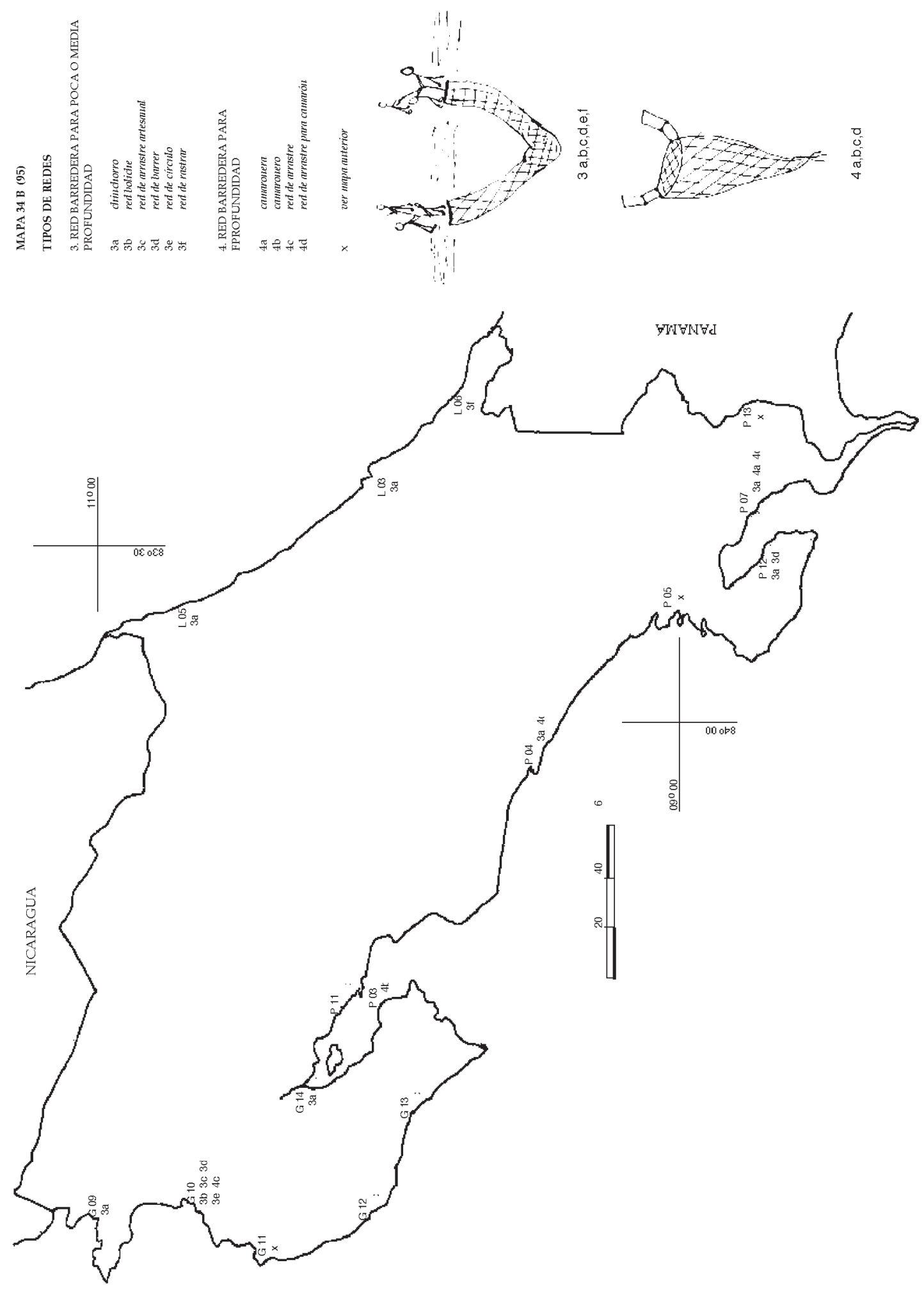

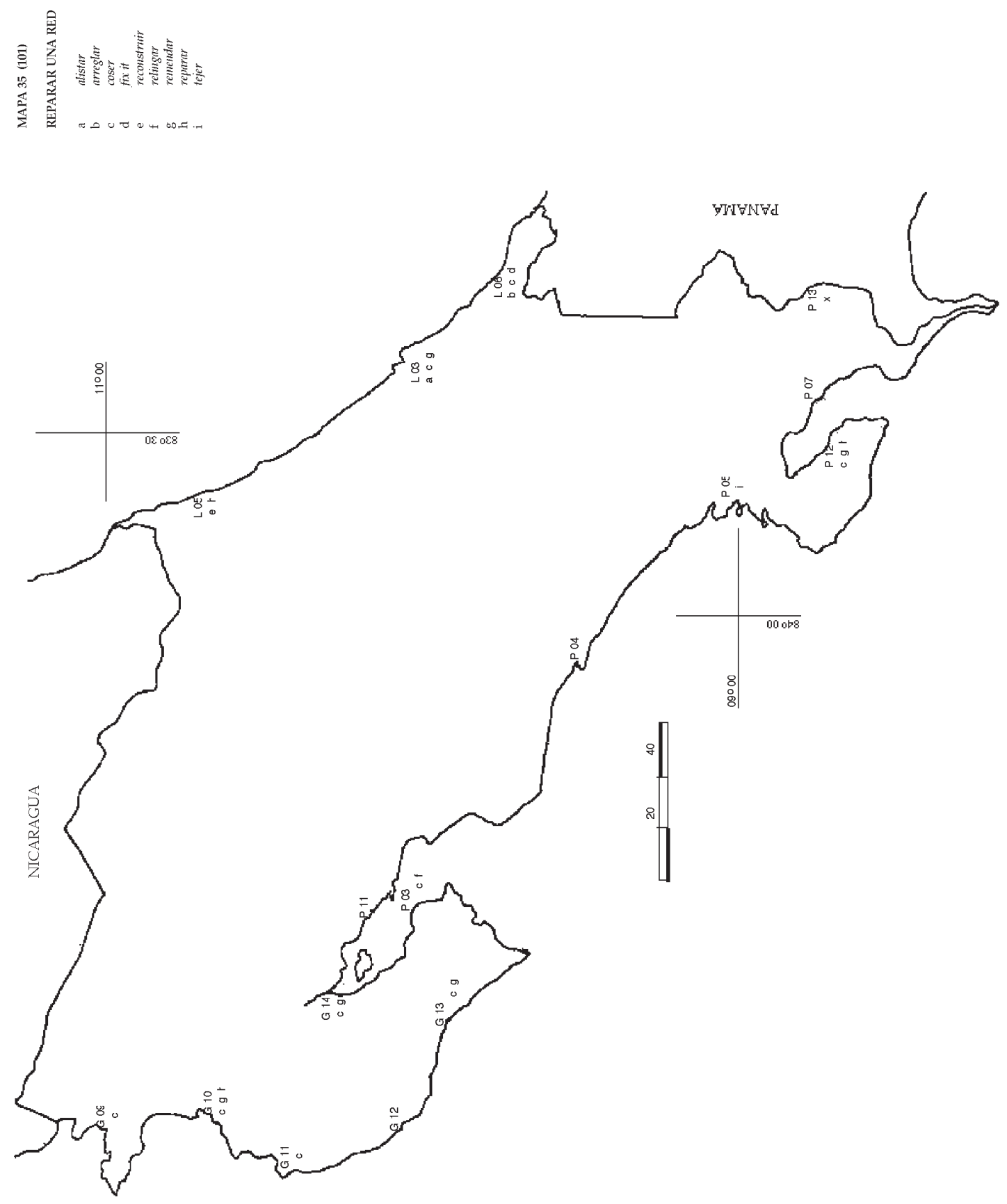

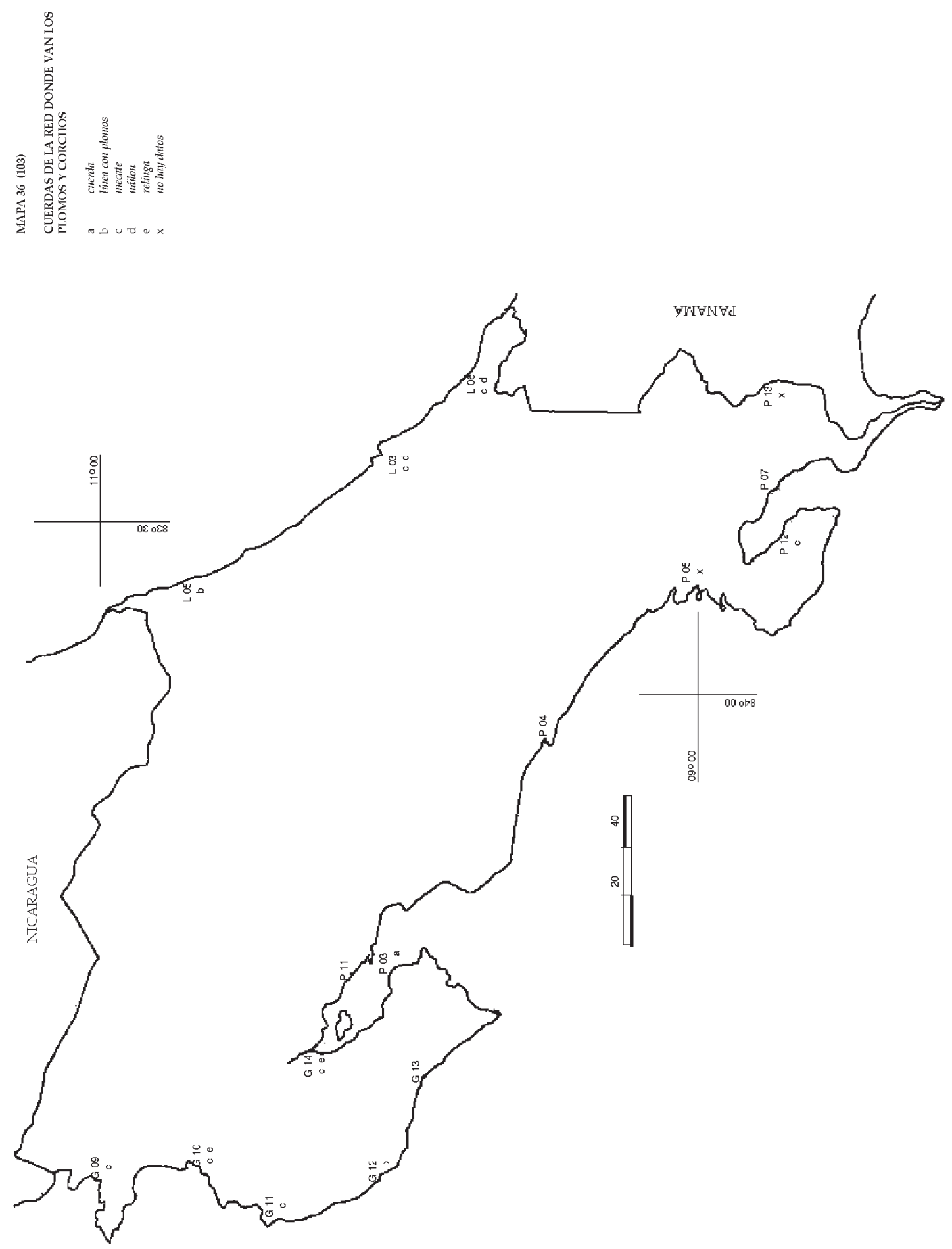

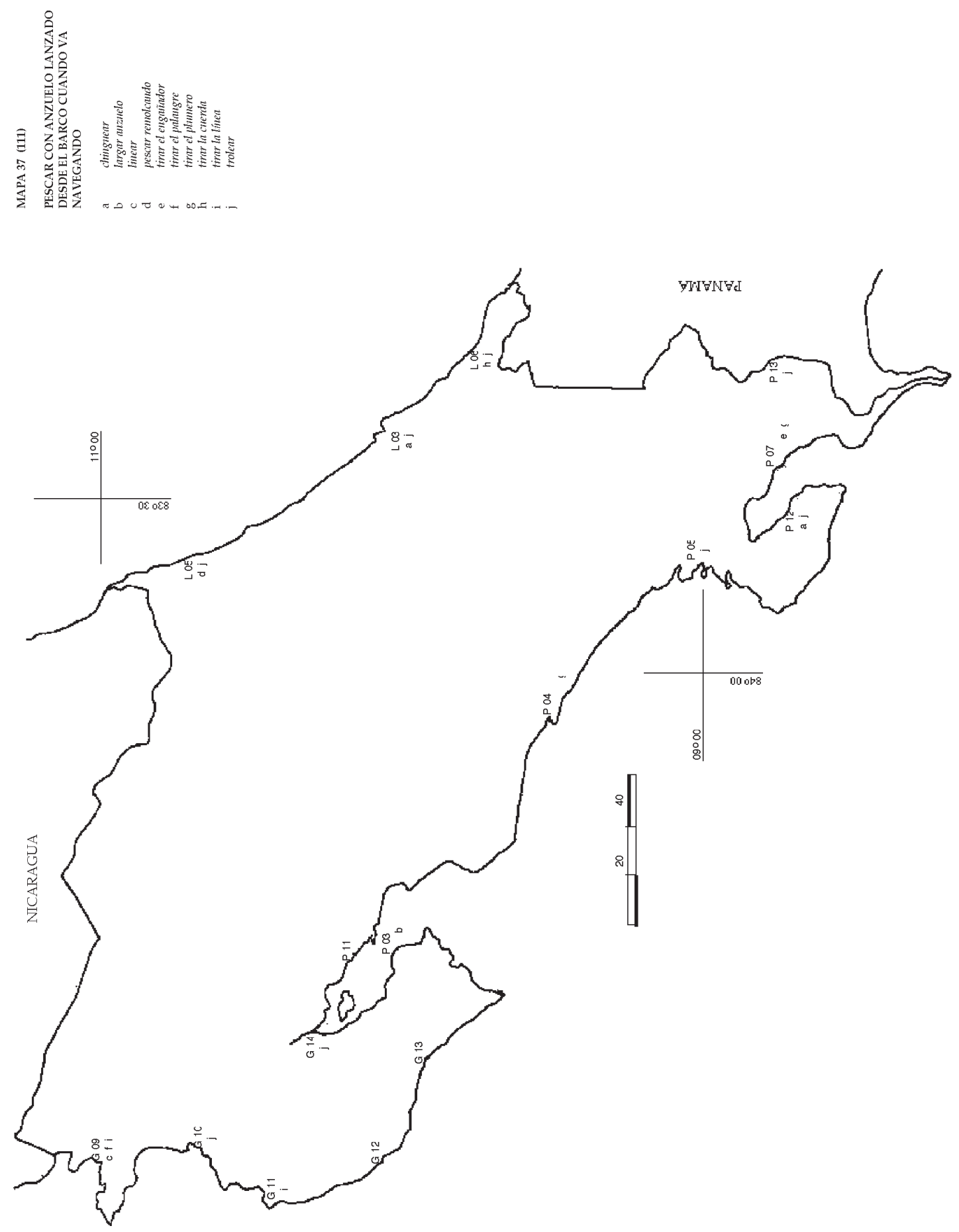

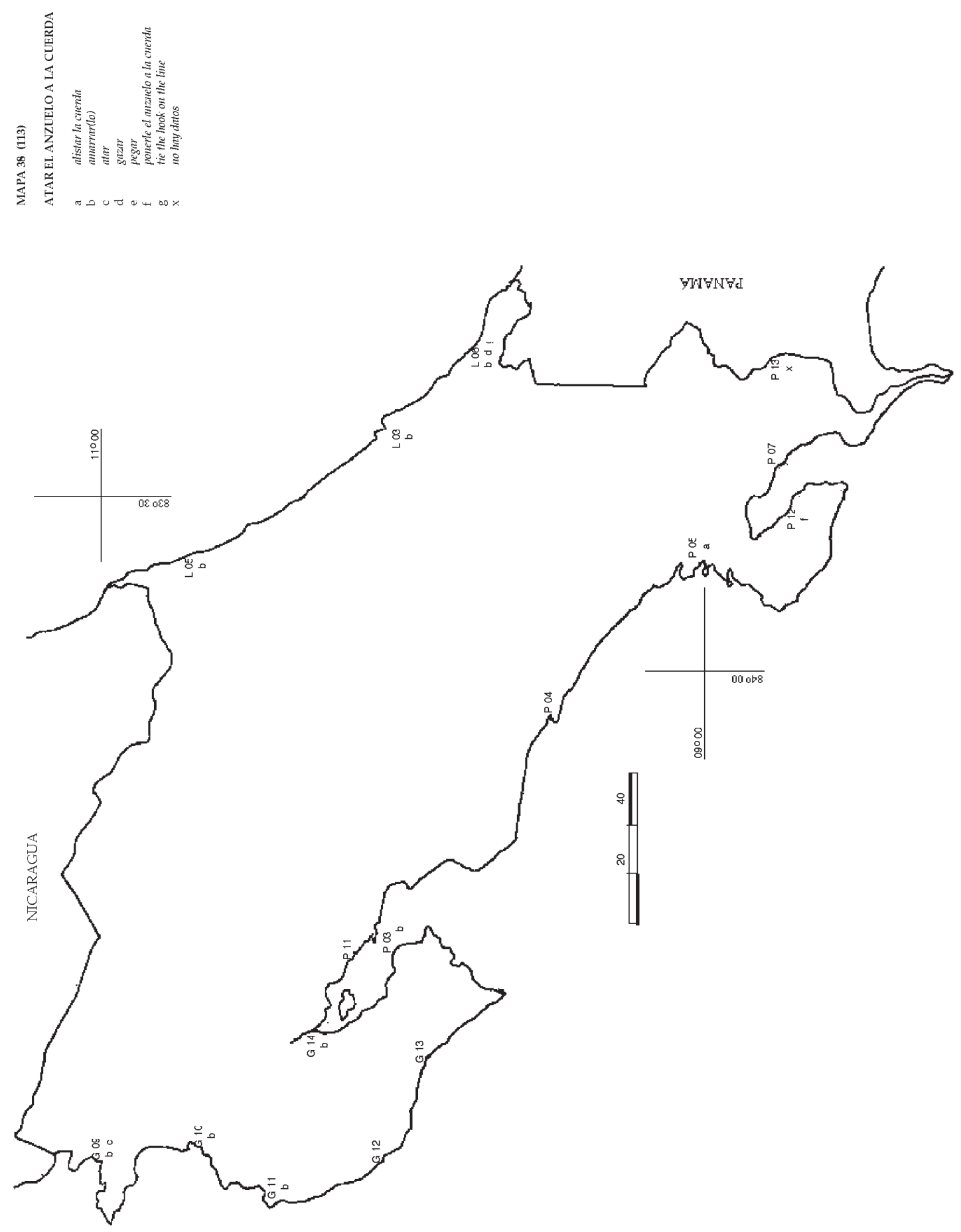

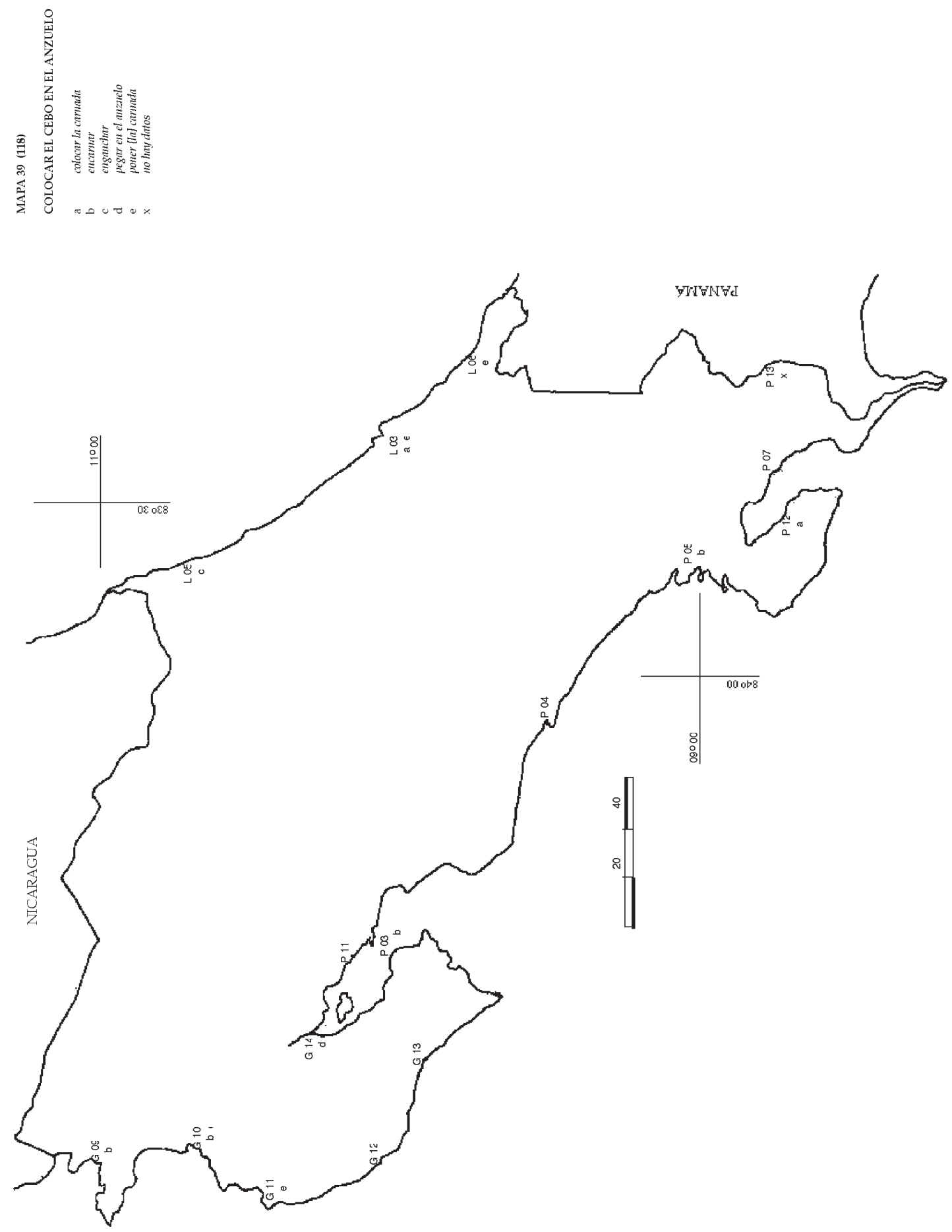

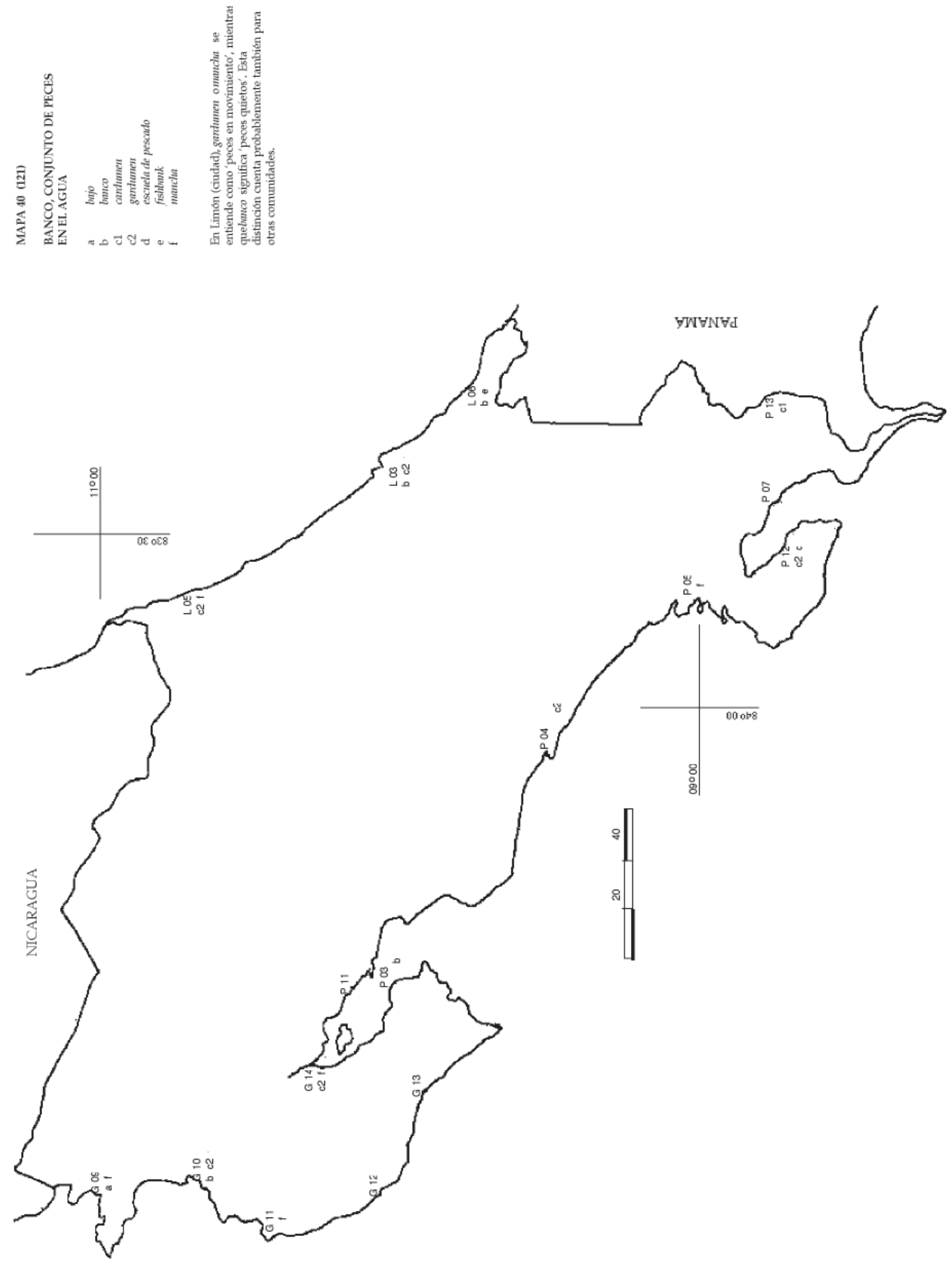

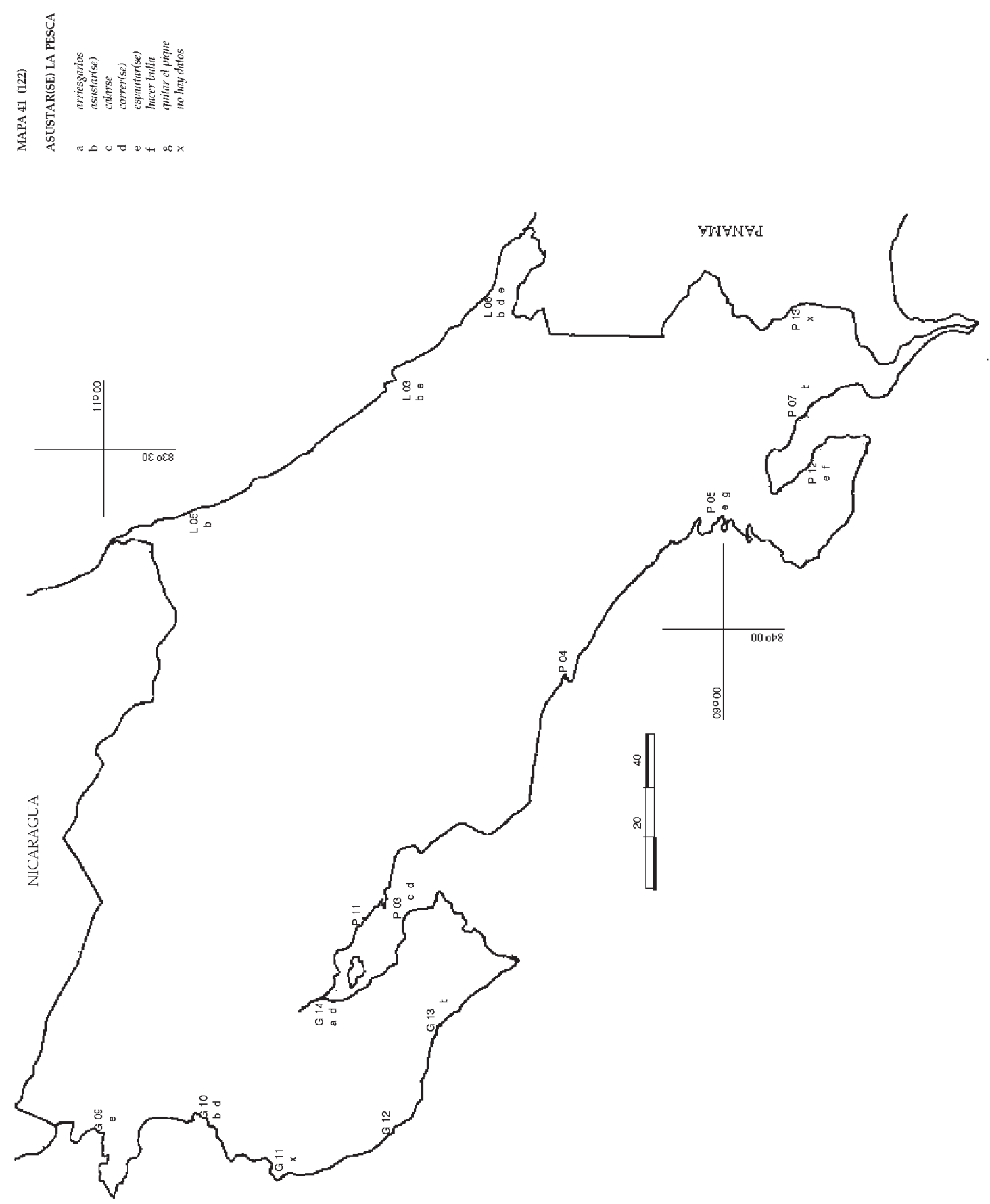

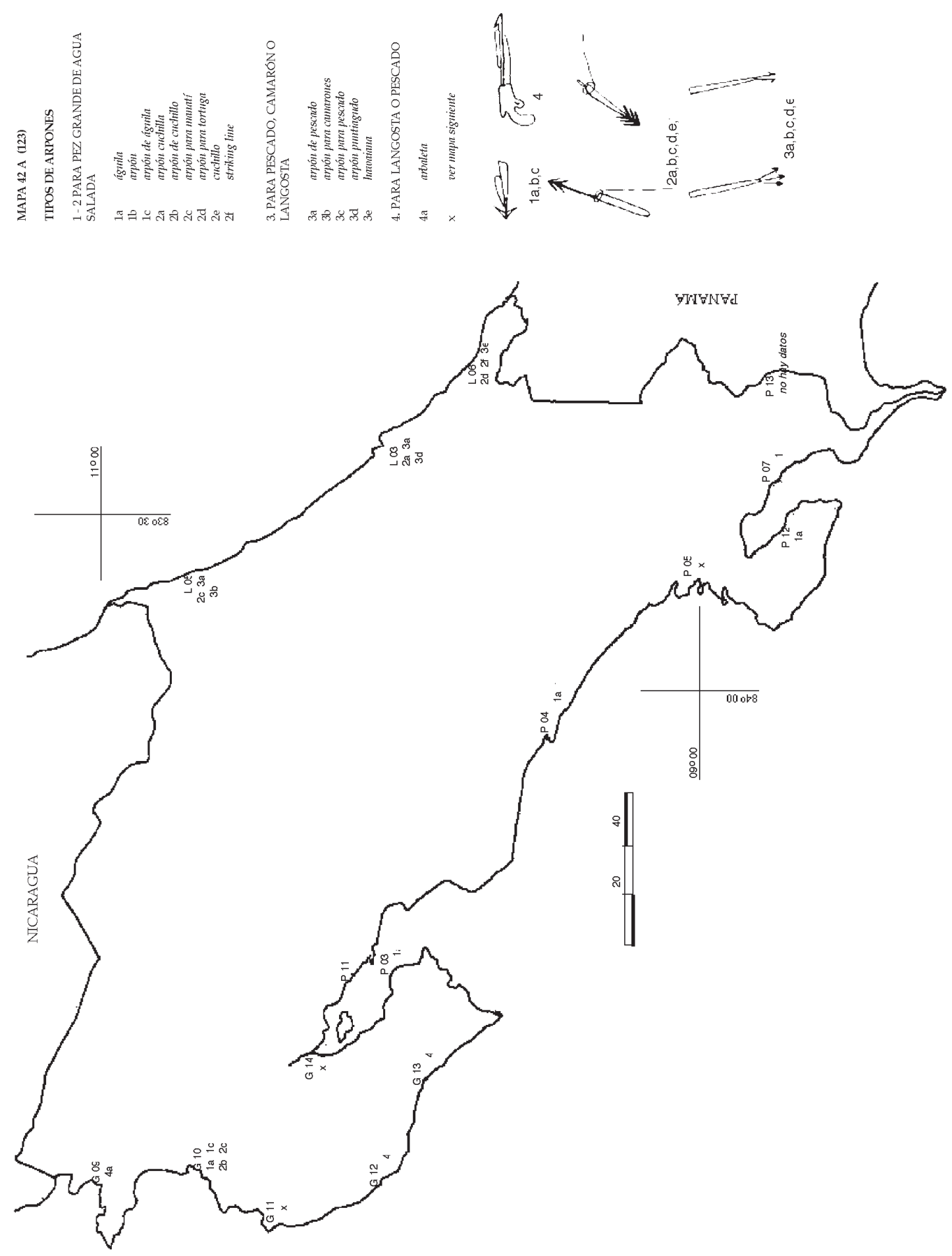

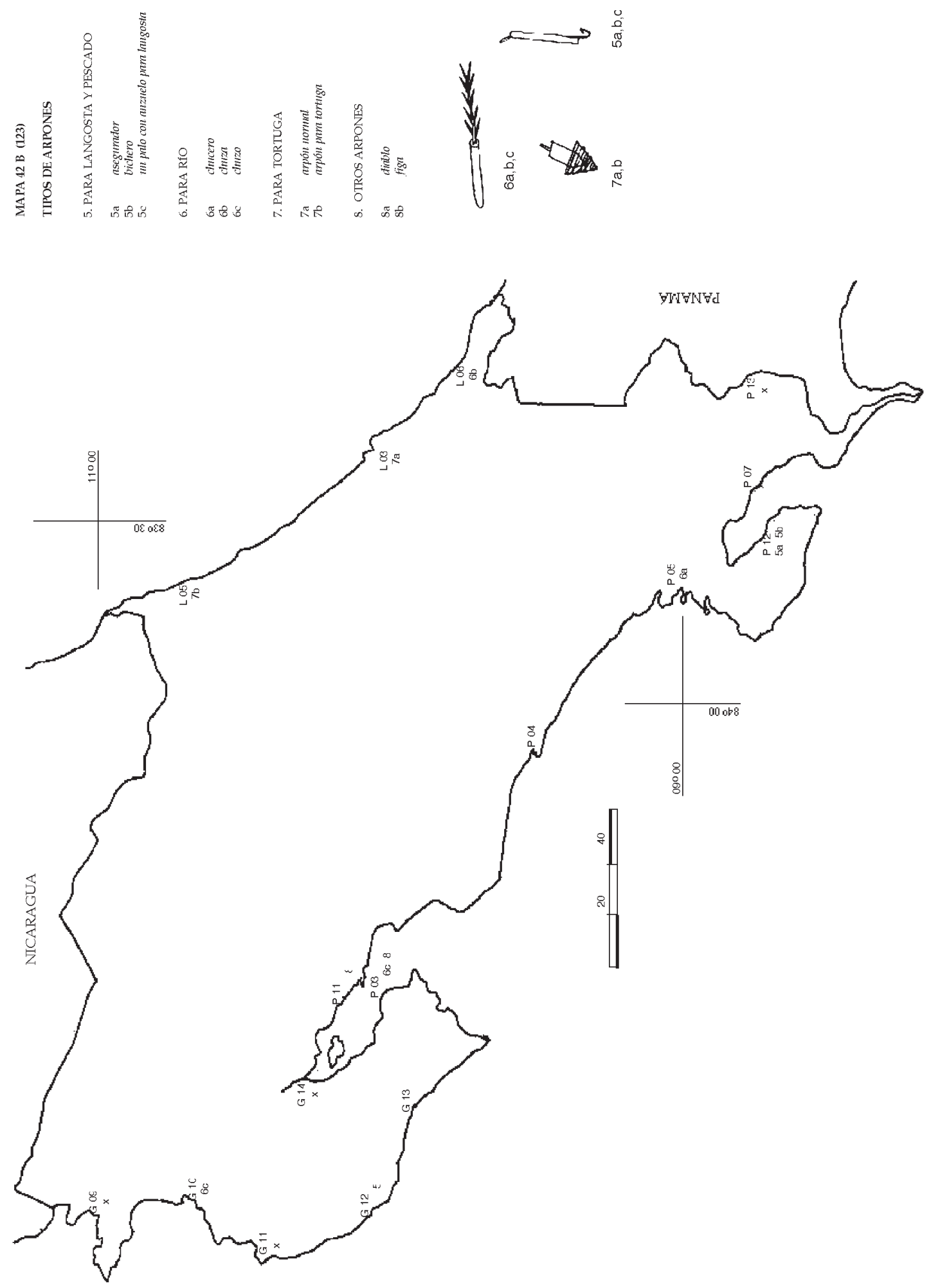

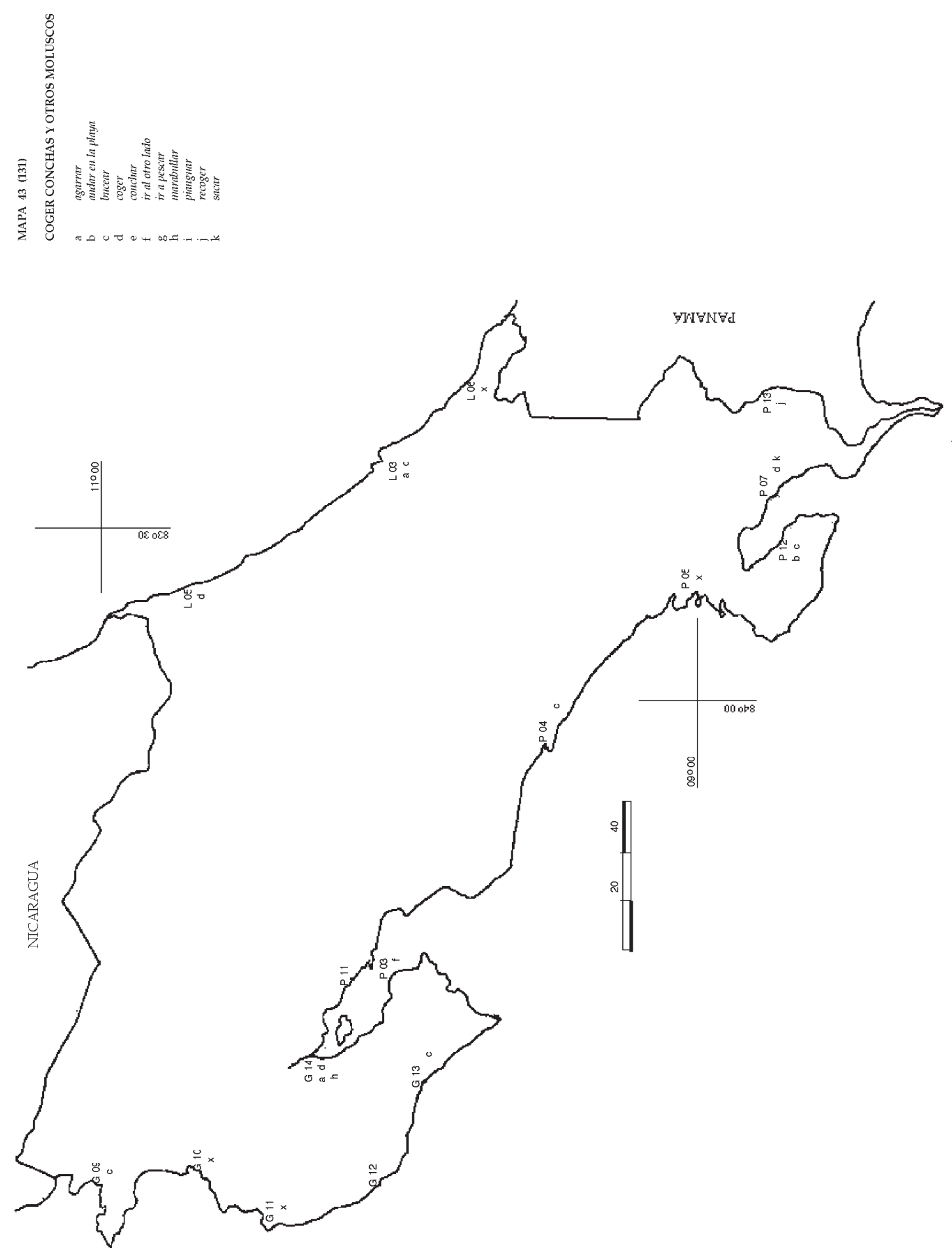


\section{Interpretación lingüístico-etnográfica de los mapas}

\subsection{Frecuencia y distribución geográfica del léxico}

Con el fin de detectar zonas dialectales, las voces se han dividido en tres categorías según su frecuencia y su distribución geográfica²:

1. Todo el país. Estas son voces registradas con distribución regular en por lo menos tres localidades de la costa pacífica y una en la costa atlántica.

2. Sólo la costa pacífica, con distribución regular sobre toda la costa, en tres lugares o más.

3. Sólo la costa atlántica, en un mínimo de dos pueblos.

Para establecer límites dialectales dentro de la costa pacífica y medir la validez de las líneas dialectales propuestas por Quesada Pacheco (1992b: 86-7), he trazado una línea divisoria en el Pacífico entre la Zona Noroeste, que va desde Cuajiniquil hasta Puntarenas, y la Zona Sur, desde Quepos hasta Paso Canoas. Para el registro de una voz como exclusiva para cada área, se siguen los mismos criterios que en la costa atlántica.

1. Voces registradas en todo el país: se registró un 9,9\% (38 lexemas) ${ }^{3}$ del total de las voces: achicador, amarrar/lo/ ${ }^{4}$, arrecife, asustar, bahía, barreal, barro, bote, bucear /conchas/, cabina, camarote, coser, costear $(v)^{5}$, costilla/s/, cresta (v), curva $/ s /$, echar el ancla (v), echar la red (v), encallar/sel, espantar, estar a la deriva, galafatear, gardumen (v), golfo, hundir/sel, ir a favor del viento (v), irse a pique, mancha, manso, mecate, ola grande, parte de atrás (v), popa, proa, remendar, reparar, trolear, volcar/sel.

2. Voces registradas únicamente en la costa pacífica, las cuales suman un $6,8 \%$ (26 lexemas) del total del vocabulario: anclar/sel, armario, bajo de arena / de piedra, bombas, bordas, calmado (v), cirial (v), coral, costados, cuadernas, encarnar, estar al garete, estero, fosforescencia (v), irse de /medio/ lado, marea, navegar a la orilla (v), navegar contra viento (v), navegar con viento en popa (v), navegar con viento en proa (v), producción (v), regar la red (etc.), relinga, rocas, tarro, virar/sel.

2.a. Voces registradas únicamente en el Noroeste: 4,1\% (16 lexemas) de las voces se han registrado sólo en la Zona Noroeste: botagua, caseta, chumaceras, estero, florecencia, fondear/sel, galón, largar el cristo / pedro, largar la red (v), manglar, marejada, picos, popa (por 'proa'), sereno, tirar la línea, varillas.

2.b. Voces registradas únicamente en el Sur, las cuales suman un 1,8\% (7 lexemas): balde, chacota, manguera /de agual, remolinos de viento, tirar el plumero, tornado, tumbar/sel. 
Por otra parte, hay un 3,6 \% (14 lexemas) de las voces, registradas únicamente en dos localidades de la costa pacífica, pero a través de las líneas dialectales establecidas por Miguel Quesada: bongo, cantil, captura, cocina, conchar, curar /un botel, drenaje, embancar, meter mecha /de piso/, navegar a favor del viento, paneta, pianguar, punta, rocas.

3. Voces registradas sólo en la costa atlántica: las cuales representan un 1,3\% (5 lexemas) del léxico total: cayuco, lestar/ perdida, ir a fondo (v), nailon (por cuerdas en que van los plomos y corchos), reef.

Los 40 mapas lingüísticos incluyen en total 381 voces. De estas, más de la mitad $-33,8$ \% (129) en la costa pacífica y 26,5 \% (101) en la atlántica- son palabras y frases que no caben dentro de ninguna de las categorías establecidas, por ser voces que aparecen en solamente una localidad en cada mapa. Este número de voces es indudablemente muy alto, aunque no son tan dominantes como parece (ver tabla 2). Incluyen la mayor parte de la gráfica debido al hecho de que palabras o expresiones únicas ocupan la misma entidad en la estadística que una voz más corriente e extendida. La tabla número 3 muestra el porcentaje de las diferentes categorías del léxico sin las voces sueltas.

Tabla 2. Distribución del léxico en todo el país, por porcentajes

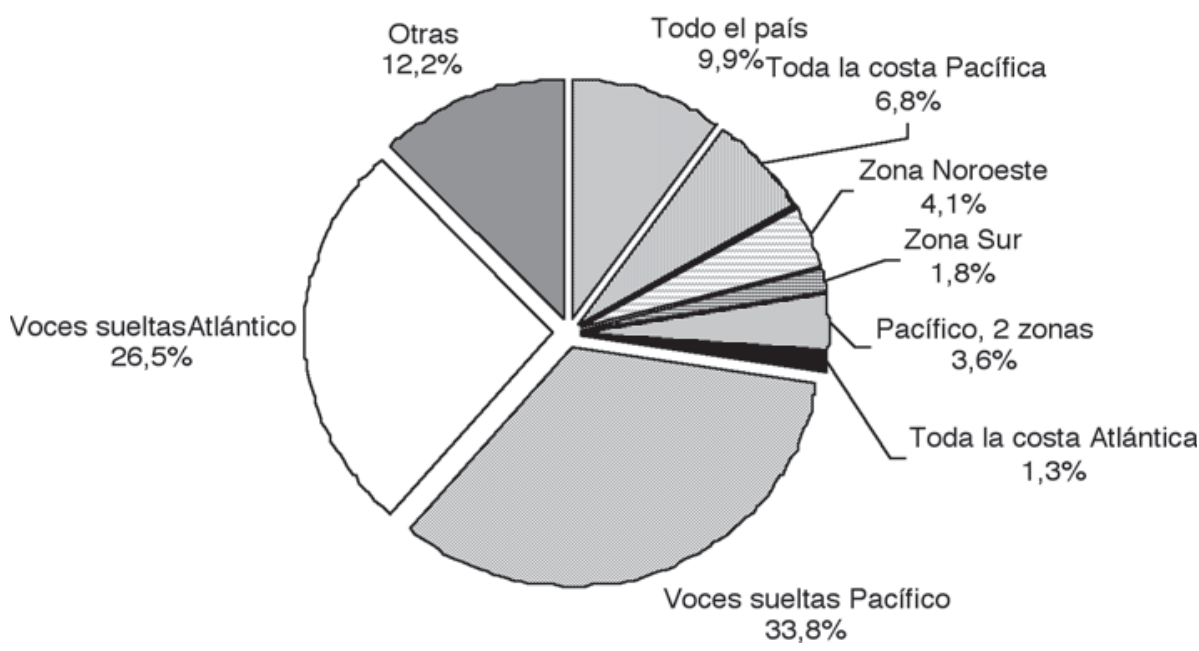

\subsection{La costa atlántica}

Conforme con la cantidad de puntos de referencia, la provincia de Limón tiene un número mucho mayor de voces sueltas que las provincias de Guanacaste y Puntarenas. Sobre todo en Puerto Viejo siempre se dan bastantes respuestas para la misma pregunta. Esto, en gran parte, se debe al hecho de que Puerto Viejo se encuentra en una zona de convergencia. No obstante, ciertas comparaciones hechas con las otras comunidades visitadas muestran que la cantidad de respuestas aumenta con el número de informantes entrevistados por separado. Puerto Viejo y Puntarenas son los pueblos que con más frecuencia tienen tres respuestas o más en cada 
mapa y son también los pueblos con más informantes entrevistados individualmente. Además, se debe tomar en cuenta que la probabilidad de registrar una voz en varios lugares aumenta en proporción a la cantidad de puntos de referencia. Para matizar el dibujo, incluimos en el análisis la cifra de la categoría 3: voces registradas sólo en la costa atlántica. El grupo ocupa solamente el 1,3\% del número total de vocablos, en comparación con 6,8\% en la costa pacífica ${ }^{6}$. El exiguo porcentaje de voces exclusivas y extensas en la costa atlántica podría indicar un vocabulario más pobre que en otras zonas, pero también podría ser un indicio de que la costa atlántica es la zona con menos homogeneidad lingüística, sin que lo uno excluya lo otro.

Tabla 3. Distribución del léxico registrado más de una vez

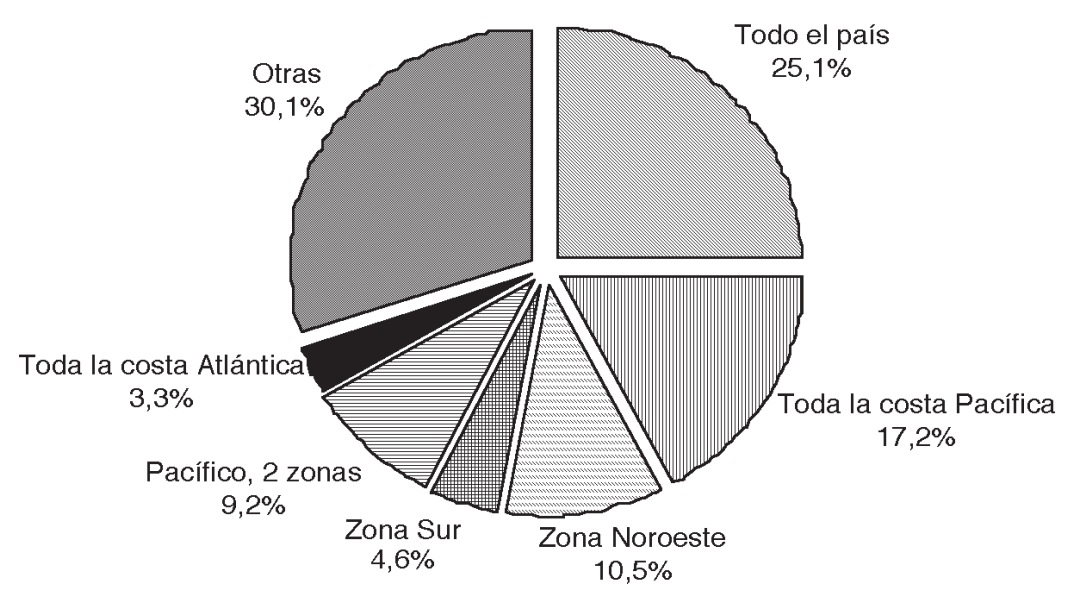

Efectivamente, la provincia de Limón es una zona lingüísticamente heterogénea. Dos de los tres puntos de referencia se encuentran en zonas fronterizas con países vecinos. En Barra del Tortuguero, la población nicaragüense de primera o segunda generación es muy grande, y no es casual que todos los informantes de dicha localidad provengan de Nicaragua de una u otra manera. En el sur de la costa, la población de origen panameño, aunque menos dominante que la nicaragüense en el norte (visto en relación con el número total de habitantes), contribuye a la diversidad demográfica del pueblo. Sin embargo, la posible influencia linguiística mutua entre Costa Rica y los países vecinos ha sido difícil de medir, ya que las tres naciones son de habla hispana, y porque el vocabulario del mar, con la excepción de El léxico del mar en Puerto Armuelles (Cáceres \& Palacios 1980), no ocupa una parte importante en las investigaciones disponibles de las zonas actuales. La concordancia que hay entre el léxico registrado como exclusivo para Costa Rica y el vocabulario usado en Puerto Armuelles indica un continuo dialectal a través de las fronteras nacionales, pero no prueba influencias particulares entre Puerto Armuelles y el sur de Costa Rica.

Las categorías establecidas para detectar líneas dialectales no pueden captar todas las tendencias que se dibujan en los mapas. Una tendencia que cae fuera es que la línea dialectal en la zona caribeña es más pronunciada entre Limón y el sur que entre Limón y el norte ${ }^{7}$, algo nada sorprendente en vista de que hay más correspondencia étnica y mejores comunicaciones entre Limón y Puerto Viejo que entre Limón y Barra del Tortuguero. 


\subsection{La costa pacífica}

De acuerdo con la estadística presentada, la costa pacífica, en comparación con la atlántica, muestra más homogeneidad lingüística y un vocabulario más amplio. La superioridad en extensión y la cantidad de puntos de referencia facilita la detección de zonas dialectales. La categoría número 2 se lleva en total 16,3\% del léxico. Un 6,8\% de las voces se registran en toda la costa pacífica: $4,1 \%$ solo en la Zona Noroeste y $1,8 \%$ únicamente en la Zona Sur. Aunque el porcentaje de voces registradas exclusivamente en el sur es bajo, se ve una clara diferencia dialectal entre esta región y la Zona Noroeste. El rasgo que más destaca es un rico vocabulario en la Zona Noroeste. Entre otras cosas, se usan bastantes metáforas humorísticas, como cristo o pedro para denotar las anclas; charco para el Golfo de Nicoya; y trapos para la red. Sin embargo, los límites entre las zonas son difusos. Muchas voces tienen su núcleo de extensión en una de las zonas en particular, aunque también ocurran fuera de los límites de esta zona. La palabra arrecife en el mapa 8, por ejemplo, brilla por su ausencia en la Zona Noroeste, pero es corriente en el sur y en el Caribe. Bajo de arena / de piedra tiene su núcleo en el norte, pero se da además en Quepos, al contrario de cirial, que en adición a su núcleo en el sur, también se ha registrado en Puntarenas ${ }^{8}$.

Un 3,6\% del léxico se da en dos localidades, pero a través de las zonas propuestas por Quesada Pacheco (1992b: 86-7). Estos ejemplos no son suficientemente uniformes como para indicar una tercera zona dialectal en el centro de la costa ${ }^{9}$, sino que más bien se presentan como un resultado del continuo dialectal entre las dos zonas susodichas. El mapa número 22 (a y b) sostiene esta suposición. No obstante, los ejemplos indican lazos dialectales particulares entre los pueblos de la Península de Nicoya, Quepos y Puerto Jiménez.

Se dan dos ejemplos de inglés fuera de la zona criolla, en Puntarenas. Estos son: bridge 'cabina donde duermen los marineros' (mapa 30), y freezer 'compartimiento para provisión de alimentos comestibles' (mapa 31). Posiblemente se deba al contacto íntimo entre Puntarenas y Norteamérica a través del comercio camaronero. De acuerdo con González Álvarez, la extracción camaronera es, en gran parte, exportada "a Miami y otras zonas de Estados Unidos" (1993: 18).

\subsection{El inglés y el criollo o mek-a-tél-yu}

Efectivamente, el grupo de ascendencia extranjera más importante de la zona caribeña es la población negra, los descendientes de obreros jamaiquinos que fueron a Costa Rica a partir de 1872 para trabajar en la construcción del ferrocarril y la explotación bananera. Su influencia en el habla de la provincia de Limón es fácil de detectar, siendo su idioma un criollo de base primordialmente inglesa "muy similar al criollo jamaiquino" (Herzfeld 1978: 17). En realidad, la cantidad extensa de voces sueltas en la zona, en gran parte se debe a la abundancia de palabras y frases criollas registradas en Puerto Viejo (tabla 4).

Aunque la lengua, conocida como mek-a-tél-yu, sustrae la mayor parte de su léxico del inglés, es, según Fernando Wright Murray, "un idioma nuevo y diferente (...) que no comparte la misma estructura ni la misma fonología de un inglés normativo" (1975: 149). Un buen ejemplo es el mismo nombre de la lengua: mek-a-tél-yu es la variante criolla para let me tell you, en inglés, o déjame decirte, en castellano. Su historia es, en breve, la siguiente: 
El negro limonense trajo de Jamaica su lengua, y la enriqueció con los aportes minoritarios de otros grupos que llegaron de otras islas antillanas (Barbados y algunas personas de islas francesas), y luego, gracias a la influencia del español la amplió aún más, vernaculizando para tal propósito palabras castizas (Meléndez \& Duncan 1993:132).

Además, la influencia del inglés norteamericano ha sido fuerte en la zona desde los tiempos de las actividades comerciales de la United Fruit Company. En la actualidad, muchos limonenses tienen familiares en Estados Unidos, se escuchan programas de radio en inglés, etc.

Las observaciones del criollo hechas en este trabajo son las siguientes ${ }^{10}: 29$ de los 43 mapas incluidos contienen una o más voces criollas provenientes de Puerto Viejo ${ }^{11}$. De Limón provienen cuatro voces ${ }^{12}$ y de Tortuguero, dos. Estas se pueden dividir en cuatro grupos principales:

1. Construcciones corrientes, que son palabras y frases que no se distinguen del inglés estándar, ni por su forma ni por su contenido semántico. Ejemplos son: big wave, foam, calm sea, swamp, to be drifting, etc. Este es el grupo más grande.

2. Construcciones con similitudes al sistema fonético del inglés, que a pesar de su forma no están registradas como inglés estándar. En Puerto Viejo seafire (mapa 5) equivale a fosforescencia del mar. La palabra correspondiente en inglés es phosphorescence (of the sea), una voz que no se da en ninguno de los pueblos visitados. Sin embargo, aparece en Limón fuego en el agua, una expresión semánticamente equivalente a seafire, pero que tampoco es denotación corriente en castellano. También hay ejemplos de voces directamente traducidas de español estándar. Para embarcación de motor (pregunta 47, no presentada en mapa), se da en Puerto Viejo tanto la palabra usual del inglés -motorboat- como una traducción directa; boat with engine, cuya construcción perifrástica es más cercana a la denotación en castellano.

3. Palabras con un nuevo aporte semántico: construcciones que existen en inglés, pero con otro significado. Un ejemplo de Puerto Viejo es stand 'parte trasera de la embarcación', un significado que no se da entre los varios usos presentados del inglés ${ }^{13}$. Scull es, en Puerto Viejo, la estaquilla a la que se ata el remo (mapa 29), pero en inglés es un tipo de remo. Este ejemplo muestra una metonimia, un desplazamiento de referencia entre dos objetos relacionados (Le Guern 1990: 34).

4. Morfología española en términos ingleses. En Tortuguero, por ejemplo, se registra pines (plural) 'cada una de las clavijas que componen la estaquilla a la que se ata el remo’ (mapa 29). En este caso, la palabra sigue la regla del castellano en la formación del plural después de consonante. En inglés, la palabra correspondiente en plural sería pins, o más exacta, thole - pins.

En adición, hay préstamos del inglés que no se consideran anglicismos en el presente trabajo, por haber sido incorporados al vocabulario castellano normativo y seguir las reglas ortográficas de éste; por ejemplo, nailon (ver tabla 4). 
Tabla 4. Porcentaje de voces en criollo e inglés

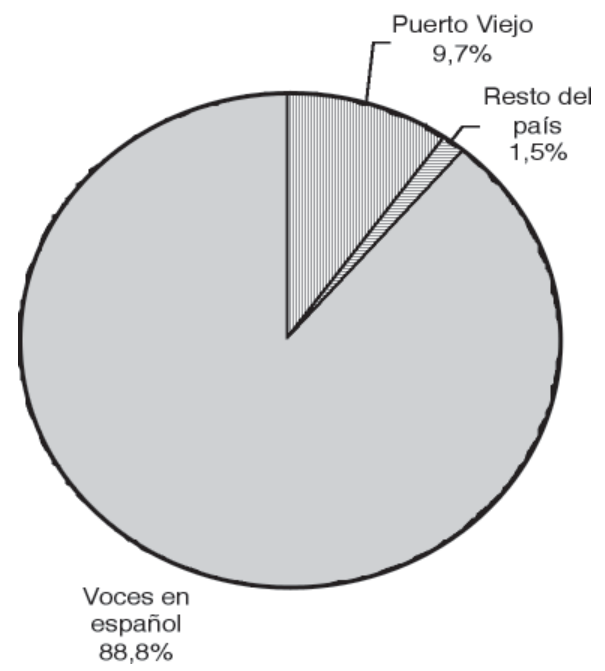

\subsection{Líneas dialectales a través de las costas}

En adición al análisis realizado, he intentado trazar eventuales líneas dialectales entre el Pacífico y el Atlántico. Hay bastantes casos de convergencia léxica exclusiva entre pueblos de cada costa, pero la mayoría parecen ser ejemplos esporádicos previsibles del vocabulario común esperado en un territorio que comparte el mismo idioma. No obstante, se repiten algunas tendencias dignas de ser contempladas. Los casos más frecuentes de similitudes léxicas se dan, en primer caso, entre Puerto Jiménez y Limón, y luego, entre Quepos, Puerto Viejo y Limón. Otro rasgo llamativo son los pocos ejemplos de similitudes que se producen únicamente entre la costa pacífica, incluso Guanacaste, y Barra del Tortuguero.

\subsection{Palabras y cosas}

Los instrumentos estudiados muestran en general una amplia extensión en ambos litorales, pero con límites claros y bastante autonomía para cada costa. De las 18 categorías de objetos ${ }^{14}$, la mitad son comunes a los dos litorales. Además, 16 se dan en el Pacífico, entre ellas siete de manera exclusiva. Por otra parte, aparecen nueve categorías en toda la costa, con una gran densidad, desde 4 hasta 10 comunidades. En comparación, 11 grupos de objetos se presentan en el Caribe, cinco de estos únicamente allí y seis en toda la costa (tabla 5). 
Tabla 5. Distribución de los objetos

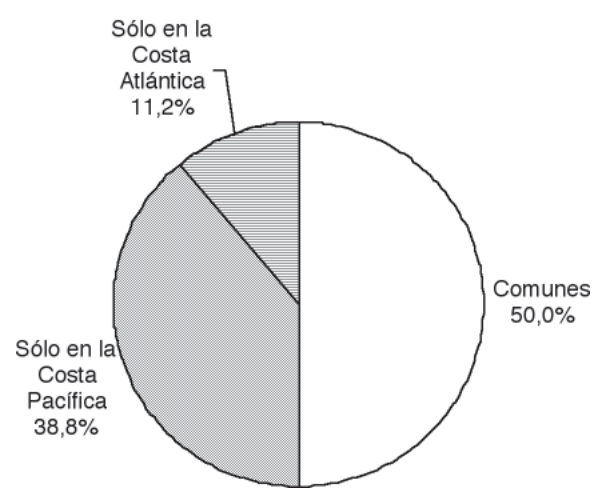

Con esto se concluye que el litoral pacífico presenta una variedad más grande de instrumentos. La selección de utensilios depende en gran parte de las condiciones geográficas de una zona, tipos de animales marinos, economía y grado de industrialización de la pesca:

Diversas condiciones de tipo natural, social, económico y estratégico, han hecho de la costa pacífica la zona de mayor rendimiento pesquero a nivel nacional. Estas condiciones favorables han facilitado el establecimiento de cierta infraestructura pesquera (...) (González Álvarez et al. 1993: 23).

De acuerdo con Gutiérrez (cit. por González Álvarez et al. 1993: 18), el litoral pacífico aporta entre un 97 y un 99\% de la producción total. Prácticamente todas las actividades pesqueras avanzadas se dirigen del Pacífico, sobre todo de Puntarenas y de otras comunidades, entre las cuales se destacan, según González Álvarez, Cuajiniquil, Playa del Coco, Quepos y Golfito. Por esto, no sorprende que la red camaronera (mapa 34 B, 4), propia de actividades pesqueras industriales o semiindustriales, se dé exclusivamente en estos pueblos.

En el Pacífico, dominan las anclas diseñadas para un subsuelo de barro, arena y roca. En el Atlántico, además de las anclas sin identificar ${ }^{15}$, domina un equipo más humilde, con fondos rudimentarios, como piedras y trozos de hierro. No es casual que este grupo de fondos también se figure en Puerto Jiménez, uno de los pueblos pesqueros más rústicos del Pacífico. Las inversiones económicas en la provincia limonense se han concentrado en la producción bananera, lo que implica "un desinterés del capital por invertir (...) en la actividad pesquera" (González Álvarez 1993: 28). Siguiendo a este autor,

La mayor inversión que se necesita para su desarrollo, está relacionada con su ausencia de embarcaciones, motores y equipos de pesca adecuados a las condiciones del mar, pero también con el desconocimiento de bancos de pesca importantes y la falta de infraestructura pesquera a bordo y en tierra (31).

Las diferentes especies de peces y animales marinos determinan el tipo de arpón usado. Como la fauna marina que se caza es muy distinta en los dos océanos, las costas no comparten la misma selección de arpones, según González Álvarez:

La pesca en el Caribe, además de ser eminentemente artesanal, es de un fuerte carácter estacional. Su importancia histórica se basa en la captura de la tortuga marina y la langosta (30).

No es de sorprender, pues, que ambos tipos de arpones para tortuga (mapa 42, 2 y 7) se presenten en la costa atlántica. 
Tabla 6. Distribución del léxico de los mapas etnográficos

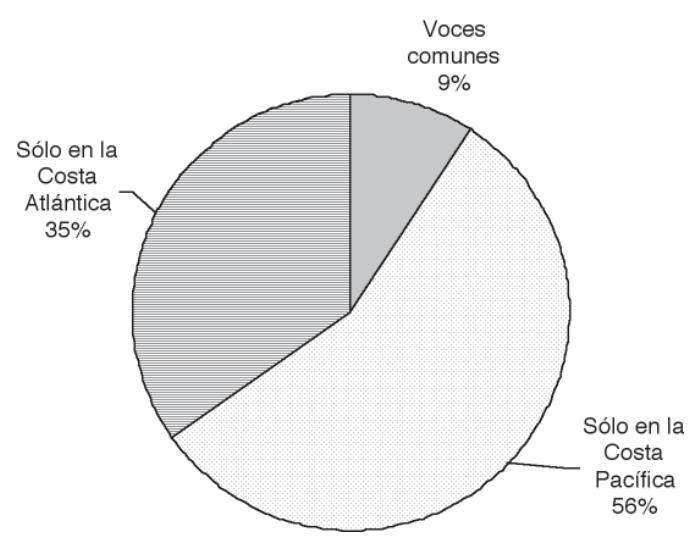

Los tres mapas etnográficos (divididos en A y B) contienen en total 66 términos y frases del tipo un palo con anzuelo para langosta. El Pacífico se lleva 43 términos, el Atlántico 29, y en total sólo 6 son comunes entre ambos. En porcentaje, la distribución del léxico será como en la tabla número 6. Profundamente influida por los instrumentos usados en cada zona, se confirma la distinción dialectal, anteriormente indicada, entre las costas. Salvo en el mapa número $27 \mathrm{~A}$, donde 1e y 2a más o menos llenan los límites difusos de la Zona Sur, curiosamente se borran las otras zonas dialectales en todo el país. Como en los mapas puramente lingüísticos, la provincia de Limón muestra más heterogeneidad en la denotación del léxico que el litoral pacífico. No obstante, esto se debe, en gran parte, a las categorías múltiples, que incluyen varios objetos.

\section{Conclusiones}

\subsection{Las zonas dialectales según los mapas}

En los mapas lingüísticos, se confirman las zonas dialectales estipuladas por Quesada para las áreas costeras. Hay una clara diferencia entre el habla de las dos costas; el vocabulario homogéneo es mayor en el Pacífico que en el Atlántico, mientras que el Atlántico tiene más voces sueltas (visto a la luz de su extensión). Esto en parte se debe a la complejidad lingüística del Caribe, con un alto grado de convergencia entre distintos idiomas. El mek-a-tél-yu se habla sobre todo en la zona desde Limón hacia la frontera panameña, aunque en este estudio el uso del idioma criollo se concentra casi únicamente en Puerto Viejo.

En la figura 1, la densidad de los puntos del dibujo corresponde a la relación dialectal entre los pueblos. Dentro del litoral Pacífico, los límites entre la Zona Noroeste y la Zona Sur son bastante difusos, una situación normal en la detección de dialectos. Como se puede apreciar en dicha figura, el área de transición, que corre más o menos entre Calle del Arreo y Quepos, muestra cierto grado de autonomía dialectal, debido a la coincidencia parcial de las dos zonas. Generalmente, el norte tiene un vocabulario más rico que el sur. Los pueblos de Quepos y Puerto Jiménez se destacan en ambos intentos por trazar conexiones dialectales a través de las zonas indicadas; las similitudes léxicas entre las dos zonas del Pacífico se ven en particular entre la Península de Nicoya, Quepos y Puerto Jiménez; entre las costas, las similitudes se dan sobre todo entre Puerto Jiménez y Limón, y entre Quepos, Puerto Viejo y Limón. 
Figura 1. Zonas dialectales de Costa Rica relativas al léxico del mar

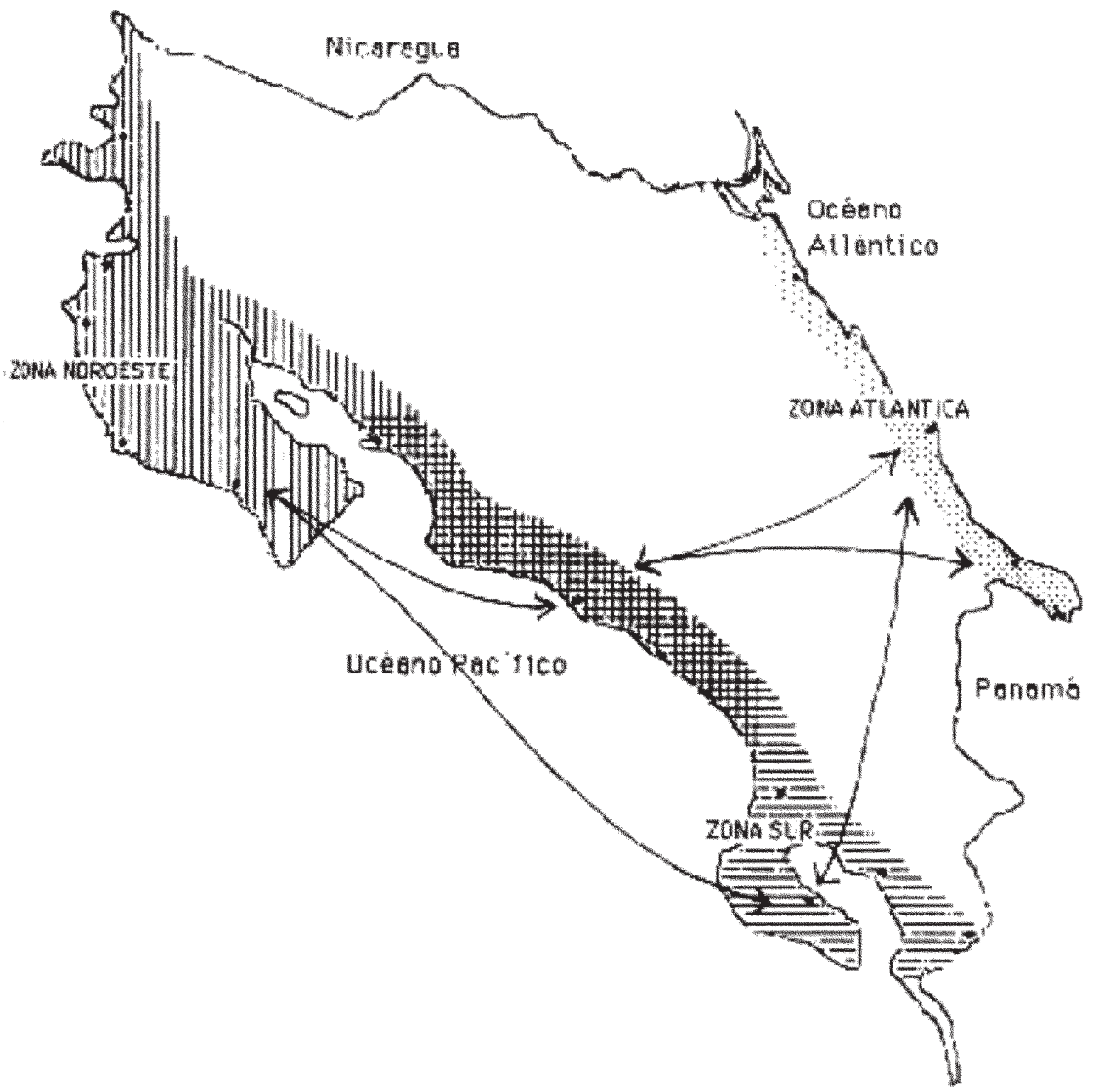

En los mapas etnográficos, se prueban las relaciones entre el ambiente económico, geográfico, cultural, etc., y el vocabulario de los pescadores, en el sentido de que las condiciones de vida influyen en la selección de instrumentos. El litoral Pacífico tiene la mejor economía, la pesca más industrializada y, por ende, el equipo más avanzado. No obstante, las zonas dialectales señaladas en los mapas puramente lingüísticos, no se confirman. En los mapas donde se repiten los mismos objetos en todo el país, también se repiten en general los mismos vocablos para denotarlos o voces relacionadas. En los mapas etnográficos, cada término denota un objeto concreto, que es idéntico, o casi idéntico, en todas las comunidades donde aparece, mientras que los puramente lingüísticos también cubren expresiones para denotar cosas más difusas y variables, que difícilmente pueden ser exactas y uniformes en toda su gama. Las diferencias entre ambos tipos de mapas señalan que los términos técnicos que denotan instrumentos hechos por hombres son más homogéneos que las voces para denotar elementos menos concretos; por ejemplo, características geográficas. 
Cuanto más específico el objeto, tanto más uniforme el término. Esta suposición se confirma incluso en los mapas lingüísticos, donde hay más homogeneidad en todo el país cuando se trata de objetos muy concretos. Sin embargo, esto también puede indicar desigualdad en el significado de las diferentes voces en los mapas lingüísticos; es decir, que las voces en cada mapa en realidad denotan cosas distintas, lo que provoca que se tracen zonas dialectales bajo criterios erróneos. Esta situación se traslada incluso al glosario. La forma del cuestionario puede sólo en parte combatir este fenómeno: si las preguntas son muy amplias, se corre el riesgo de tener respuestas con diferentes significados; si son demasiado restringidas, no tendrán vigencia para todas las comunidades. Una pregunta que tuve que eliminar por esta razón fue la número 70, que buscaba el nombre del agujero por el que pasa la cadena del ancla. Esto es característico de las embarcaciones grandes, pero en muchos de los pueblos pequeños de pesca artesanal no se usa. La polémica presentada prueba, más que nada, la legitimidad y la importancia de los mapas etnográficos en un trabajo como el presente. Nunca se puede eliminar el riesgo de tener sinónimos falsos en un mapa, porque el ambiente de cada pueblo es único, algo que se refleja en el habla de sus habitantes.

Ahota bien, en los mapas etnográficos se pueden documentar y cartografiar las diferencias ambientales a través de las cuales se reflejan cambios idiomáticos, evitando así malos entendidos. En el proceso de detectar zonas dialectales, los mapas puramente lingüísticos defienden los intereses de los elementos lingüísticos que son imposibles de representar en mapas etnográficos. Muestran, además, las consecuencias del hecho de que el idioma se desarrolla en varias direcciones debido, entre otras cosas, al ambiente de los hablantes. De esta manera, los dos tipos de mapas se complementan.

Naturalmente, los mapas también muestran sinónimos reales. Normalmente, un objeto se puede llamar de varias maneras, incluso dentro de la misma zona. En este trabajo se señala que la cantidad de sinónimos o maneras de expresar un fenómeno está relacionada con la cantidad de informantes entrevistados por separado. Esta afirmación tiene, sin embargo, una excepción llamativa: Puerto Jiménez cuenta con sólo dos informantes, pero tiene casi la misma cantidad de voces sueltas que Puntarenas ${ }^{16}$, con seis informantes, lo que muestra que otros criterios también juegan su parte en la formación de los mapas.

Finalmente, tuve experiencias positivas con el uso de diferentes maneras de entrevistar a los informantes: las entrevistas individuales gozaban de más tranquilidad y posibilidades para profundizar y aclarar ambigüiedades; las colectivas daban mucha información en menos tiempo y eran excelentes para obtener pequeñas distinciones entre sinónimos.

\subsection{Problemas pendientes}

Con el fin de obtener conclusiones más exactas sobre el léxico del mar, se podría tener un corpus más grande y una red de puntos más densa. Esto último cuenta sobre todo para las áreas más difusas, que son la zona norte en la costa atlántica y la región entre las dos zonas dialectales en la costa pacífica, entre Puntarenas y Ciudad Cortés.

Para presentar un objeto en un mapa etnográfico, es necesario tener un buen conocimiento de tal objeto. Es un trabajo pulcro ganar una visión de conjunto sobre cada instrumento, pero vale la pena, por las razones mencionadas anteriormente. En el presente trabajo queda bastante material apto para presentar en mapas etnográficos, y sería deseable seguir la cartografía de los objetos para tal finalidad. Con esto, se podría revelar posibles 
sinónimos falsos obtenidos aquí; por ejemplo, de las diferentes partes de la embarcación, $\mathrm{y}$, en el último instante, combatir o afirmar las conclusiones establecidas por mí.

Echo de menos una investigación que trabaje más a profundidad la relación lingüística

entre los diferentes grupos demográficos de la costa atlántica. El presente trabajo puede ser el punto de partida para un estudio comparativo sobre el léxico del mar a través de las fronteras con los países vecinos, con el enfoque en voces castellanas o criollas. También en este contexto quiero mencionar los mapas etnográficos; sería muy interesante averiguar posibles diferencias en la selección de instrumentos debido a las fronteras nacionales y su efecto en el idioma. Naturalmente, también sería interesante realizar una investigación de tal carácter en las zonas fronterizas en la costa pacífica.

\section{Notas}

1. Tres de los mapas serán lingüístico-etnográficos.

2. Para compensar la diferencia en la cantidad de puntos de referencia de las zonas, las exigencias mínimas sobre la frecuencia de una voz varían. Ya que la aportación semántica de un lexema o un vocablo no es uniforme, la interpretación de sus límites geográficos se hace para cada mapa por separado, aunque la misma palabra aparezca en otra localidad en otro mapa.

3. El número entre paréntesis es la cantidad exacta de las voces que se registró en cada categoría.

4. Las palabras o partes de palabras entre barras son variantes que se dan en algunos sitios.

5. La letra $v$ en paréntesis significa que otras variantes de la voz están incluidas.

6. Más el total de $9,5 \%$ en los otros grupos bajo la categoría 2.

7. $\quad$ Ver por ejemplo el mapa número 17 (j).

8. $\quad$ Otros ejemplos en mapas 9 (a), 11 (g), 23 (j), 26 (a), 32 (h), etcétera.

9. He buscado tal zona más o menos entre Calle del Arreo y Ciudad Cortés, que es el área más difusa.

10. Remito a las investigaciones de Fernando Wright Murray o Terry A. Wolfe para una descripción amplia del criollo limonense.

11. Están incorporados también los mapas etnográficos.

12. En el presente trabajo las voces criollas se concentran en Puerto Viejo porque los negros de Limón no se pusieron a disposición para entrevistas.

13. Se consultaron el Longman Lexicon of Contemporary English (1987), el Longman Dictionary of Contemporary English (1987), The Oxford Guide to the English Language (1981), The Consise Oxford Thesaurus (1995), The Concise Oxford Dictionary (1995), The Collins Spanish - English Dictionary (1987).

14. Tres grupos incluyen cosas diversas. Estos son: 5 y 6 del mapa número 27, y 8 del mapa número 42 .

15. Las denotaciones son más detalladas en la costa pacífica en parte debido al hecho de que visité primero el litoral atlántico, sin el conocimiento detallado sobre los diferentes utensilios que iba ganando poco a poco, con la experiencia del trabajo de campo.

16. En Puntarenas llevé a cabo tanto entrevistas de grupo como individuales. 


\section{Bibliografía}

Abellán, J. L. 1972. La Idea de América. Origen y evolución. Madrid: Ediciones Istmo.

Agüero, A. 1962. El español de América y Costa Rica. San José: Atenea.

1964. "El español en Costa Rica y su atlas lingüístico". Presente y futuro de la lengua española. Madrid: OFINES. Tomo 1, 135-152.

Akman, Haçi. Sin fecha. Kurdisk identitet. Sin editorial.

Alvar, Manuel. 1969. Estructuralismo, geografía lingüística y dialectología actual. Madrid: Editorial Gredos S. A.

1975. Atlas lingüístico - etnográfico de las Islas Canarias. (2 volúmenes). Gran Canaria: Ediciones del Cabildo Insular.

(ed.). 1977. Terminología marinera del Mediterráneo. Comisión española del A.L.E., Madrid.

1993. Estudios Canarios. Tomo II. Islas Canarias: Colección Clavijo y Fajardo.

Alvar, Manuel; Llorente, A.; Salvador, G. 1963-64. Atlas lingüístico - etnográfico de Andalucía. (5 volúmenes). Granada: Publicaciones de la Universidad de Granada.

Alvar, Manuel; Llorente, A.; Buesa, T. y Alvar, E. 1979. Atlas lingüístico - etnográfico de Aragón, Navarra y Rioja. 12 tomos. Zaragoza: Diputación Provincial, Dep. de Geografía Lingüística, Institución Fernando el Católico.

Alvar, Manuel y Quilis, A. 1984. Atlas lingüístico de Hispanoamérica. Cuestionario. Madrid: Instituto de Cooperación Iberoamericana.

Araya, G. (red.), Contreras, C., Wagner, C., \& Bernales, M. 1973. Atlas lingüístico-etnográfico del Sur de Chile. Valdivia: Instituto de Filología de la Universidad Austral de Chile y Editorial Andrés Bello.

Auer, Peter y Luzio, Aldo di (ed.). 1988. Variation and Convergence. Studies in Social Dialectology. Berlin, New York: Walter de Gruyter.

Bescht, Werner et al. 1982. Dialektologie. Ein Handbuch zur deutschen und allgemeinene Dialektforschung. Erster Halbband. Berlin - New York, Walter de Gruyter.

Buesa, T. y Florez, L. 1981-82. Atlas lingüístico - etnográfico de Colombia. 6 tomos. Bogotá: Instituto Caro y Cuervo.

Bugge, Hans Erik. 1996. El léxico de los animales domésticos en el Valle Central y las Zonas Noroeste y Norte de Costa Rica. Tesina de Hovedfag: Universidad de Bergen.

Butler, Cristopher. 1985. Statistics in Linguistics. Nueva York: Basil Blackwell Ltd. 
Cáceres, O. M. y D. Palacios. 1980. El léxico del pescador en Puerto Armuelles. David: Universidad de Panamá, Facultad de Filosofía, Letras y Educación.

Castellón, H. A. 1939. Diccionario de Nicaragueñismos. Managua Talleres Nacionales.

Chambers, J.K. y P. Trudgill. 1980. Dialectology. Cambridge: Cambridge University Press.

Collado, Jesús Antonio. 1978. Fundamentos de Lingüística General. Madrid: Editorial Gredos.

Coseriu, Eugenio. 1985. El hombre y su lenguaje. Madrid: Editorial Gredos.

Dickeman, Margaret. 1985. "Eliminación de la ambigüedad pronominal en el discurso del criollo limonense". Revista de Filología y Lingüística de la Universidad de Costa Rica. XI (1): 119 - 130.

Francis, W.N. 1983. Dialectology. An introduction. Londres y Nueva York: Longman Group Limited.

Gagini, Carlos. 1892. Diccionario de barbarismos y provincialismos de Costa Rica. San José: Tipografía Nacional.

1918. Diccionario de costarriqueñismos. San José: Imprenta Nacional.

Gellner, Ernest. 1959. Words and Things. Londres: Victor Gollancz Ltd.

Goebl, H. (ed.). 1984. Dialectology. Bochum: Studienverlag Dr. N. Brockmeyer.

Gómez Córdoba, C. E. 1975. Vocabulario cafetero de la provincia de Cartago. Tesis de Licenciatura: Universidad de Costa Rica.

González Álvarez, L., et al. 1993. Comunidades pesquero - artesanales en Costa Rica. Heredia: Editorial de la Universidad Nacional.

Guitart, Jorge M. y Joaquín Roy (ed.). 1980. La estructura fónica de la lengua castellana: fonología, morfología, dialectología. Barcelona: Editorial Anagrama.

Guitart, Jorge M. y Juan C. Zamora Munné. 1988. Dialectología hispanoamericana. Teoría, descripción, historia. Salamanca: Ediciones Almar.

Gulden, C. M. van der. 1994. Vocabulario nicaragüense. Managua: Editorial UCA. Colección Alternativa. Serie Habla Nicaragüense $N^{\circ} 1$.

Haber H. (ed.). 1994. Costa Rica. Insight Guides. APA Publications Ltd.

Hernández, C. et al. 1991. El español de América. Actas del III Congreso Internacional del Español de América. Valladolid, 3 a 9 de julio de 1989. Tres volúmenes. Salamanca: Junta de Castilla y León.

Herzfeld, Anita. 1978. "Vida o muerte del criollo limonense.” Revista de Filología y Lingüística de la Universidad de Costa Rica. IV (2). 
1994. "Language and Identity: The Black Minority of Costa Rica." Revista de Filología y Lingüística de la Universidad de Costa Rica. XX (1): 113 - 142.

Jaberg, K. y Jud, J. 1931. Sprach- und Sachatlas des Italiens und der Südschweiz. 2 volúmenes. Zofingen: Verlagsanstalt Ringier \& Co.

Kirkpatrick, B. (comp.). 1995. The Concise Oxford Thesaurus. A Dictionary of Synonyms: Londres - Nueva York - Sydney - Toronto: BCA.

Kunnskapsforlaget. 1989. Store norske leksikon. 15 tomos. Oslo: Aschehoug \& Gyldendals forlag.

Le Guern, Michel. 1990. La metáfora y la metonimia. 5a ed. Madrid: Ediciones Cátedra, S.A.

Lope Blanch, J. M. 1975. "Delimitación de las zonas dialectales de México: objetivos y problemas". Hispania. 58.

1989. Estudios de lingüística hispanoamericana. México: Universidad Nacional Autónoma de México.

1990. Atlas lingüístico de México. México: El Colegio de México, Fondo de Cultura Económica.

Louis, Betzy Bell. 1997. El léxico del cuerpo humano en Costa Rica: Análisis dialectológicosemántico. Tesina de Hovedfag: Universidad de Bergen.

Luzio, Aldo di y Peter Auer (ed.). 1988. Variation and Convergence. Studies in Social Dialectology. Berlín, Nueva York: Walter de Gruyter.

Lyons, John. 1991. Semantics: 1. Cambridge: Cambridge University Press.

Masís Morales, Oscar y Elizabeth Mora Lobo. 1985. "Las oraciones completivas en el criollo de Limón: Análisis sintáctico de un idiolecto". Revista de Filología y Lingüística de la Universidad de Costa Rica. XI (2): 111 - 121.

Mc Arthur, T. 1987. Longman Lexicon of Contemporary English. Londres: Longman Group UK Limited.

Meléndez, C. y Q. Duncan. 1993. El negro en Costa Rica. 10. ed. San José: Editorial Costa Rica.

Meza, Hortensia. 1980. El habla de los sabaneros liberianos y tilaranenses. Estudio léxico - semántico con anotaciones fonológicas, morfológicas y sintácticas. Tesis de Licenciatura: Universidad de Costa Rica.

Moliner, María. 1994. Diccionario de uso del español. Dos tomos. Madrid: Gredos.

Montes Giraldo, José Joaquín. 1970. Dialectología y Geografía Lingüística: Notas de Orientación. Bogotá: Publicaciones del Instituto Caro y Cuervo. 
Montes Giraldo, José Joaquín. 1973. Muestra del léxico de la pesca en Colombia. Bogotá: Publicaciones del Instituto Caro y Cuervo.

1982. Dialectología general e hispanoamericana. Orientación teórica, metodología y bibliografía. Bogotá: Instituto Caro y Cuervo.

1983. "Habla, lengua e idioma”. Thesaurus. XXXVIII: 325-339.

1993. Motivación y creación léxica en el español de Colombia. Bogotá: Publicaciones del Instituto Caro y Cuervo.

Moreno Fernández, F. 1990. Metodología sociolingüística. Madrid: Editorial Gredos.

Muñiz Rodríguez, V. 1989. Introducción a la filosofía del lenguaje. Problemas ontológicos. Barcelona: Anthropos. Editorial del Hombre.

Navarro, T. 1948/1974. El español en Puerto Rico. Universidad de Puerto Rico: Editorial Universitaria.

Petyt, K. M. 1980. The Study of Dialect. An introduction to dialectology. Londres: The Language Library. André Deutsch Ltd.

Portilla Chaves, Mario. 1993. "Fonemas segmentales en el criollo inglés de Limón". Revista de Filología y Lingüística de la Universidad de Costa Rica. XIX (2): 89 - 97.

Quesada Pacheco, Miguel Ángel. 1981. Análisis sociológico del español de San Gabriel, Monterrey y La Legua de Aserrí. Tesis de Licenciatura: Universidad de Costa Rica.

1985. Diccionario regional de los distritos de San Gabriel, Monterrey y la Legua de Aserrí. San Gabriel de Aserrí: Centro de Producciones Audiovisuales.

1991. El español de Guanacaste. San José: Editorial de la Universidad de Costa Rica.

1992a. El español en Costa Rica. San José: Editorial Fernández - Arce.

1992b. "Pequeño atlas lingüístico de Costa Rica". Revista de Filología y Lingüística de la Universidad de Costa Rica. XVIII (2): 85-190.

1992c. Atlas Lingüístico - etnográfico de Costa Rica. Cuestionario. San José: Editorial Nueva Década.

1996. Nuevo diccionario de costarriqueñismos. Segunda ed. Cartago: Editorial Tecnológica de Costa Rica.

Real Academia Española. 1996. Diccionario de la lengua española. 21. edición. Madrid: Espasa Calpe.

Revilla, Ángel. 1976. Panameñismos. Panamá: Roysa. 
Román, J. M. 1976. El uso del español en Desamparados de Alajuela. Tesis de Licenciatura: Universidad de Costa Rica.

Roy, Joaquín y Jorge M. Guitart. (ed.). 1980. La estructura fónica de la lengua castellana Fonología, morfología, dialectología. Barcelona: Editorial Anagrama.

Sánchez, V. 1983. Cuestionario lingüístico costarricense. San José: Editorial de la Universidad de Costa Rica.

Smith et. al. 1987. Collins Spanish - English English - Spanish Dictionary. Londres - Glasgow: Collins.

The Oxford Guide to the English Language. 1983. Londres: Guild Publishing.

Thomas, Alan R. (ed.). 1988. Methods in Dialectology. Clevedon, Philadelphia: Multilingual Matters LTD.

Thompson, D. (ed.). 1995. The Concise Oxford Dictionary. Ninth edition. BCA, Londres Nueva York - Sydney - Toronto: BCA.

Thun, Harald. 1990. Atlas lingüístico diatópico - diastrático del Uruguay. Bamberg - Stuttgart: Franz Steiner Verlag.

Vindas Chaves, F. 1971. Vocabulario del banano. Tesis de Licenciatura: Universidad de Costa Rica.

VOX. 1988. Diccionario manual ilustrado de la lengua española. Barcelona: Bibliograf S/A.

Wenker, G. 1881. Sprachatlas des Deutschen Reiches. Marburgo - Berlin.

Wilson, J. 1970. A Generative Phonological Study of Costa Rican Spanish. Tesis doctoral: Universidad de Michigan.

Wrede, F. et al. 1926. Deutscher Sprachatlas. Marburg: Elwert.

Wright, Fernando M. 1975. "Un análisis sintáctico del habla criolla de Limón". Revista de Filología y Lingüística de la Universidad de Costa Rica. vol. I (2).

1982. "Problemas y métodos para la enseñanza del inglés como segunda lengua a los hablantes del Mek-a-tel-yu en la provincia de Limón". Revista de Filología y Lingüística de la Universidad de Costa Rica. VIII (1 y 2).

Zgusta Ladislav (ed.). 1980. Theory and Method in Lexicography: Western and Non - Western Perspectives. South Carolina - Columbia: Hornbeam Press, Incorporated. 